\title{
Clinical Outcomes of Aspirin Interaction with Other Non-Steroidal Anti- Inflammatory Drugs: A Systematic Review
}

Zuhair Alqahtani and Fakhreddin Jamali

Faculty of Pharmacy and Pharmaceutical Science, University of Alberta, Edmonton, Alberta, Canada.

Received, March 16, 2018; Revised, March 30, 2018; Accepted, April 25, 2018; Published, April 27, 2018.

\begin{abstract}
Purpose: Concomitant use of some non-Aspirin nonsteroidal anti-inflammatory drugs (NANSAIDs) reduces the extent of platelet aggregation of Aspirin (acetylsalicylic acid). This is while many observational studies and clinical trials suggest that Aspirin reduces cardiovascular (CV) risk attributed to the use of NANSAIDs. Thus, the therapeutic outcome of the interaction needs to be assessed. Methods: We searched various databases up to October 2017 for molecular interaction studies between the drugs and long-term clinical outcomes based on randomized clinical trials and epidemiological observations that reported the effect estimates of $\mathrm{CV}$ risks (OR, RR or HR; 95\% CI) of the interacting drugs alone or in combinations. Comparisons were made between outcomes after Aspirin alone, NANSAIDs alone and Aspirin with naproxen, ibuprofen, celecoxib, meloxicam, diclofenac or rofecoxib. Results: In total, 32 eligible studies (20 molecular interactions studies and 12 observational trials) were found. Conflicting in vitro/in vivo/ex vivo platelet aggregation data were found for ibuprofen, naproxen and celecoxib. Nevertheless, for naproxen, the interaction at the aggregation level did not amount to a loss of cardioprotective effects of Aspirin. Similarly, for ibuprofen, the results overwhelmingly suggest no negative clinical CV outcomes following the combination therapy. Meloxicam and rofecoxib neither interacted with Aspirin at the level of platelet aggregation nor altered clinical outcomes. The clinical outcomes data for celecoxib and diclofenac are in conflict. Conclusion: Aspirin appears to maintain its cardioprotective effect in the presence of naproxen, ibuprofen, meloxicam and rofecoxib. The limited available data suggest that the effect of interaction at the platelet aggregation level may dissipate shortly, or the reduced platelet aggregation yielded by the interaction may be sufficient for cardioprotection; i.e., no need for near complete aggregation. In addition, cardioprotective effect of Aspirin, despite reduced platelet aggregation caused by NANSAIDs, may be through its involvement in other mechanisms such as the renin-angiotensin system and/or metabolism of arachidonic acid to biologically active compounds mediated by cytochrome P450.
\end{abstract}

This article is open to POST-PUBLICATION REVIEW. Registered readers (see "For Readers") may comment by clicking on ABSTRACT on the issue's contents page.

\section{INTRODUCTION}

Acetylsalicylic acid (Aspirin) is in clinical use since mid $19^{\text {th }}$ century. In addition to being an effective analgesic, antipyretic and anti-inflammatory agent, it is used, among other indications, for its anti-platelet property to reduce all-cause mortality, cardiac death, and nonfatal myocardial infarction (MI) (1). Moreover, low-dose Aspirin, alone or in combination, is recommended for the secondary prevention of acute ischemic stroke and transient ischemic attack (2-4). In general, the anti-platelet effect of Aspirin accounted for the irreversible inhibition of platelet cyclooxygenase-1 (COX-1) enzyme. COX-1 is an enzyme that catalyzes AA to produce several prostaglandins (PG), among them thromboxane $\mathrm{A}_{2}\left(\mathrm{TxA}_{2}\right)$, a promoter of platelet aggregation $(5,6)$. The inhibition of the COX-1 dependent $\mathrm{TxA}_{2}$ by Aspirin, measured by plasma thromboxane $\mathrm{B}_{2}\left(\mathrm{TxB}_{2}\right)$ is recommended to be near completion to significantly inhibit platelet function in vivo (7-9).

The non-Aspirin nonsteroidal anti-inflammatory drugs (NANSAIDs) are among the most commonly used medications for a variety of indications ranging from headaches to arthritis. NANSAIDs bind and inhibit the COX enzymes which lead to inhibition of prostanoids biosynthesis including PGs, prostacyclins and thromboxanes (10). Thus, the concomitant use of some NANSAIDs appear to interact with the Aspirin's anti-platelet function, thereby, although unproven,

Corresponding Author: Fakhreddin Jamali, Faculty of Pharmacy \& Pharmaceutical Sciences, 11361 - 87 Avenue, Edmonton, Alberta, Canada T6G 2E1; fjamali@ualberta.ca 
may reduce its $\mathrm{CV}$ protection benefits (11). This, however, seems contradictory to the observations that the elevated CV risks of some NANSAIDs is lowered by addition of low dose Aspirin to the regimen $(12,13)$. We, therefore, hypothesized that the $\mathrm{CV}$ benefits of Aspirin are reduced upon concomitant administration of NANSAIDs. We tested the hypothesis through a comprehensive systematic search of available literature data to assess the $\mathrm{CV}$ risks of concomitant use of NANSAIDs and Aspirin with those of Aspirin alone or NANSAID. Subsequently, the clinical outcomes were compared with the results of the AspirinNANSAIDs interactions at the molecular level; i.e., in vitro, in vivo and/or ex vivo data. The present analysis focuses on only six commonly used NANSAIDs, i.e., ibuprofen, naproxen, diclofenac, celecoxib, rofecoxib, and meloxicam.

\section{METHODS}

This systematic review with a trial registration number of PROSPERO 2018 CRD42018084556 has been carried out according to the Preferred Reporting Items for Systematic Reviews and Meta-Analyses (PRISMA) guidelines as listed in the Supplements (14).

\section{Search strategy}

The study focus was only on ibuprofen, naproxen, diclofenac, meloxicam, celecoxib and rofecoxib. Both authors independently searched published studies indexed in MEDLINE, EMBASE, CINAHL, Web of Science, and the Cochrane Library (Cochrane Central Register of Controlled Trials, Cochrane Database of Systematic Reviews, Database of Abstracts of Reviews of Effects, Cochrane Methodology Register, Health Technology Assessment, and NHS Economic Evaluation Database) from inception to October 2017. The search terms were compiled from the names of individual NANSAIDs, acetylsalicylic acid, Aspirin, cyclooxygenase, COX, cardiovascular, myocardial infarction, stroke, cerebrovascular, cardioprotection, platelet, platelet aggregation, platelet aggregation inhibit, antiplatelet effect, blood platelets, and drug interaction. The detailed search strategy is provided as supplementary material. We also searched the Clinical Trials Registry platforms for ongoing studies for any additional relevant references. The bibliographies of included reports were searched for relevant additional studies. Abstracts and unpublished studies were not included.

\section{Study selection and data extraction}

Both authors examined the titles and abstracts of studies to identify studies that potentially meet the inclusion criteria. The inclusion criteria were as follows: (i) Randomized controlled trials (RCTs) or observational studies (cohort or case-control studies) that include treatment with Aspirin alone or NANSAID alone as well as concomitant use of NANSAIDs with Aspirin. The association between the treatments and risk of CV (MI), cerebrovascular events (stroke) or all-cause mortality were assessed for studies that included odds ratios (ORs), relative risks (RRs) and/or hazard ratios (HRs) with 95\% confidence interval (CI). (ii) molecular interactions trials (in vitro, in vivo or ex vivo) in human addressing the interaction at the platelet level between NANSAIDs and Aspirin.

The full texts of these potentially eligible studies were retrieved and independently assessed for eligibility. Disagreements were settled through discussion and consensus. Extracted information included study information (i.e. authors, location, publication date, type of study, number of participants, and study duration), patient characteristics (i.e. age, sex, previous CV events including stroke, Aspirin use, and NANSAIDs use), intervention and comparator (i.e. drugs and doses) and outcomes (i.e. events/total for all study population or subgroups).

The identified studies were excluded if: (i) they were reviews, questionnaire, thesis, letters, simulated studies, meeting summary, conference abstracts, editorial or commentary articles; (ii) had no eligible outcomes or did not report direct comparisons of individual NANSAIDs; (iii) used extra-oral route of administration (e.g., topical use for analgesia) or used other drugs with NANSAIDs or Aspirin.

\section{Quality assessment}

The methodological quality of the included observational studies (cohort and case-control studies) was appraised using scales adopted from the Newcastle-Ottawa quality scale (NOS) (15). Based on the study design (cohort or case-control study), each study was evaluated using the appropriate scoring system. Eight items in the included cohort and case-control studies were identified and assessed. Cohort and case-control studies with 6-9, 
3-5, and 0-2 points were classified as high, fair or poor quality, respectively.

\section{RESULTS}

\section{Eligible studies}

Our search strategy yielded 3,563 potentially relevant articles from which 3,498 were found ineligible because they were not epidemiological studies or molecular interactions experiments. Sixtyfive articles underwent full-length article review. Twenty-five of these were excluded because they did not report the outcome of interest (MI or stroke), 5 were excluded because they did not report direct comparison of individual NANSAIDs with or without use of Aspirin, and 3 were excluded because of combination other than Aspirin with NANSAIDs or use of formulation other than oral. Twelve studies (5 cohort studies and 7 case-control studies) with 80,845 events met our eligibility criteria and were included in the analysis $(12,13,16-25)$. The eligible studies scored good quality based on the calculated NOS scores (cohorts, 8-9/9 and case-controls 6-8/9) (Table 9).

Twenty molecular interactions studies addressing the interactions between NANSAIDs and Aspirin were included. The detailed flow chart of search methodology and selection process is shown in Figure 1. Table 1 compares the outcomes of both platelet effects and clinical outcomes. Data on the selected NANSAIDs are provided in Tables 2-7. The detailed characteristics of molecular interactions experiments studies are described in Table 8. The clinical data on the interactions between Aspirin and different type of NANSAIDs are summarized in Table 9.

\section{Platelet aggregation}

The 20 eligible molecular interaction studies with the information on the interactions indicated that, in general, the anti-platelet effect of Aspirin is reduced in the presence of ibuprofen, naproxen or celecoxib (Tables 1 and 8). However, meloxicam, rofecoxib and diclofenac do not interfere with the anti-platelet effect of Aspirin.

\section{Cardiovascular outcomes}

The 12 studies $(12,13,16-23)$ listed in Tables 1 and 9 reported CV risks of Aspirin alone as well as in combination with various NANSAIDs. The results suggest that the addition of naproxen to an Aspirin regimen does not result in a loss of beneficial effects of the latter (Tables 1 and 3). Similarly, the reported ibuprofen-Aspirin interaction at the level of platelets does not seem to diminish the cardioprotective effect of Aspirin (Table 1). However, 2 of the 10 eligible studies have reported diminished clinical benefit of Aspirin caused by ibuprofen $(17,24)$. Indeed, one of the 2 studies (17) has made the same observation for celecoxib and diclofenac (Table 1). As depicted in Table 2, there are only two studies $(24,25)$ that found changes in all-cause mortality for Aspirin plus ibuprofen compared with Aspirin alone users. One of these studies (25) found that addition of ibuprofen did not increase the risk of all-cause mortality (HR, 0.84; CI 0.70-1.01) but the other one (24) did (HR, 1.93; CI 1.30-2.87). The latter also found an increased risk of $\mathrm{CV}$ mortality for the combination (HR, 1.73; CI 1.05-2.84).

Table 1. Summary of in vitro, in vivo, ex vivo and clinical data on the interactions between Aspirin and different type of NANSAIDs

\begin{tabular}{|c|c|c|c|c|c|c|}
\hline \multirow{3}{*}{$\begin{array}{l}\text { NANSAIDs } \\
\text { Ibuprofen }\end{array}$} & \multicolumn{4}{|c|}{ Anti-platelet effect of Aspirin diminished } & \multicolumn{2}{|c|}{$\begin{array}{l}\text { Beneficial effect of Aspirin in } \\
\text { reducing } \mathrm{CV} \text { risks diminished }\end{array}$} \\
\hline & \multicolumn{2}{|c|}{ in vitro } & \multicolumn{2}{|c|}{ in vivolex vivo } & \multicolumn{2}{|c|}{ Clinical data } \\
\hline & & Yes $^{(26-28)}$ & No ${ }^{(29)}$ & Yes ${ }^{(30-36)}$ & $\mathrm{No}^{(12,18-23,25)}$ & Yes $^{(17,24)}$ \\
\hline Naproxen & No ${ }^{(26)}$ & Yes $^{(37)}$ & No ${ }^{(38)}$ & Yes $(34-37,39)$ & $\mathrm{No}^{(12,16-19,23)}$ & \\
\hline Diclofenac & $\mathrm{No}^{(26,27)}$ & & No ${ }^{(30,31,38)}$ & & $\mathrm{No}^{(19,23)}$ & Yes $(12,17)$ \\
\hline Celecoxib & & Yes ${ }^{(27)}$ & No $(32,34,35,40)$ & Yes $(41)$ & No ${ }^{(12,13)}$ & Yes $(17)$ \\
\hline Rofecoxib & \multicolumn{2}{|c|}{ NA } & No ${ }^{(30,42)}$ & & No $(12,13,17)$ & \\
\hline Meloxicam & No ${ }^{(26)}$ & & No ${ }^{(43)}$ & & No $(12,16)$ & \\
\hline
\end{tabular}


Table 2. Reports of concomitant ibuprofen/Aspirin use regarding CV/all-cause mortality risks.

\begin{tabular}{|c|c|c|c|}
\hline \multicolumn{2}{|c|}{$\begin{array}{c}\text { Beneficial effect of Aspirin in reducing CV risks NOT } \\
\text { diminished }\end{array}$} & \multicolumn{2}{|c|}{$\begin{array}{l}\text { Beneficial effect of Aspirin in reducing } \\
\text { CV risks diminished }\end{array}$} \\
\hline Reference & $\begin{array}{c}\text { Conclusions } \\
(\mathrm{RR} / \mathrm{OR} / \mathrm{HR}(\mathbf{9 5 \%} \mathrm{CI}))\end{array}$ & Reference & $\begin{array}{c}\text { Conclusions } \\
(\mathrm{RR} / \mathrm{OR} / \mathrm{HR}(\mathbf{9 5 \%} \mathrm{CI}))\end{array}$ \\
\hline (12) & $\begin{array}{l}\text { RR for MI: Aspirin+ibuprofen, } 1.22(0.83- \\
\text { 1.78); Aspirin alone, } 1.04(0.96-1.12) \\
\text { ibuprofen alone, } 1.02(0.80-1.32)\end{array}$ & (17) & $\begin{array}{l}\text { HR for MI: Aspirin+ibuprofen, } 1.50 \text { (1.33- } \\
1.70) \text {; Aspirin alone } 0.98(0.94-1.03) \text {. }\end{array}$ \\
\hline (18) & $\begin{array}{l}\text { RR for MI: Aspirin+ibuprofen, } 1.28(1.16- \\
1.40) \text {; ibuprofen alone, } 1.12(1.06-1.19) \text {. }\end{array}$ & (24) & $\begin{array}{l}\text { HR for all-cause mortality: } \\
\text { Aspirin+ibuprofen, } 1.93 \text { (1.30-2.87) vs } \\
\text { Aspirin alone; HR for CV mortality: } 1.73 \\
(1.05-2.84) \text { vs Aspirin alone. }\end{array}$ \\
\hline (19) & $\begin{array}{l}\text { HR for MI: Aspirin+ibuprofen, ever exposed, } \\
1.01(0.58-1.76), \geq 30 \text { days: } 1.13(0.54-2.39), \\
\geq 60 \text { days: } 1.83(0.76-4.42) \text { vs nonexposed } \\
\text { subjects. }\end{array}$ & & \\
\hline (20) & $\begin{array}{l}\text { OR for MI: Aspirin+ibuprofen, } 0.74(0.57- \\
0.97) \text {; Aspirin alone, } 0.87(0.75-1.00)\end{array}$ & & \\
\hline (21) & $\begin{array}{l}\text { RR for MI: Aspirin+ibuprofen, } 0.61(0.50- \\
0.73) v s \text { Aspirin alone users. }\end{array}$ & & \\
\hline (22) & $\begin{array}{l}\text { OR for MI: Aspirin+ibuprofen, } 1.01 \text { ( } 0.47- \\
2.20) v s \text { Aspirin alone; Aspirin+ibuprofen, }> \\
4 \text { times/week, } 2.03(0.60-6.84) \text {; } \\
\text { Aspirin+ibuprofen, }<4 \text { times/week, } 0.60 \\
(0.21-1.66) \text {. }\end{array}$ & & \\
\hline (23) & $\begin{array}{l}\text { OR for MI: Aspirin+ibuprofen, } 1.08 \text { (0.74- } \\
\text { 1.58) vs Aspirin alone users. }\end{array}$ & & \\
\hline (25) & $\begin{array}{l}\text { HR for death: Aspirin+ibuprofen, } 0.84(0.70- \\
1.01) \text { vs Aspirin alone users. }\end{array}$ & & \\
\hline
\end{tabular}

RR, Risk Ratio; OR, Odds Ratio; HR, Hazard Ratio; CV, Cardiovascular; MI, Myocardial Infarction. Ratios for Aspirin are listed when the assessment is made $v s$ nonusers; for others, the ratio is 1 as Aspirin is used as the reference.

Table 3. Reports of concomitant naproxen/Aspirin use regarding CV risks.

\section{Beneficial effect of Aspirin in reducing $\mathrm{CV}$ risks NOT diminished}

\section{Reference}

(12) RR for MI: Aspirin+naproxen, 1.26 (0.60-2.62); Aspirin alone, 1.04 (0.96-1.12); naproxen alone, 1.00 (0.68-1.47).

(16) OR for MI: Aspirin+naproxen, 1.04 (0.65, 1.67); naproxen alone, 1.21 (0.93-1.56).

(17) HR for CV: Aspirin+naproxen, 0.94 (0.52-1.70); Aspirin alone 0.98 (0.94-1.03).

(18) RR for MI: Aspirin+naproxen, 1.28 (1.07-1.53); naproxen alone, 1.11 (1.01-1.23).

(19) HR for MI: Aspirin+naproxen, ever exposed, 1.04 (0.58-1.76), $\geq 30$ days, 1.13 (0.54-2.39), $\geq 60$ days, 1.83 (0.76-4.42) vs nonexposed subjects.

(23) OR for MI: Aspirin+naproxen, $0.96(0.49-1.86) v s$ Aspirin alone users.

RR, risk ratio; OR, odds ratio; HR, hazard ratio; CV, Cardiovascular; MI, Myocardial Infarction. Ratios for Aspirin are listed when the assessment is made $v s$ nonusers; for others, the ratio is 1 as Aspirin is used as the reference.

A trend towards an increase in the rate of recurrent MI has been reported in one cohort study when subjects exposed to Aspirin and ibuprofen (HR, 1.50; CI 1.33-1.70) compared with Aspirin alone users (HR, 0.98; CI 0.94-1.03) (17). A retrospective cohort study has also concluded that patients with history of $\mathrm{CV}$ diseases had increased risk of mortality when exposed to Aspirin plus ibuprofen compared with users of Aspirin alone (24). 


\section{DISCUSSION}

This is, to the best of our knowledge, the first systematic review that compares published AspirinNANSAIDs interaction at the platelet level with its long-term clinical outcomes. We have used broad inclusion criteria in many databases to capture molecular interactions experiments, RCTs and observational studies for a range of NANSAIDs and Aspirin users. However, no RCTs data were found.

We found that a NANSAID-Aspirin interaction at the platelet level does not necessarily amount to a loss of beneficial effects of Aspirin. Indeed, for naproxen, studies have consistently reported no negative clinical outcomes after addition of the drug to the Aspirin regimens (Table 3). Similarly, studies overwhelmingly suggest that Aspirin maintains it beneficial effects after addition of ibuprofen to the regimen. (Table 2).

As expected, the cardioprotective effect of Aspirin is not diminished by meloxicam and rofecoxib, two NANSAIDs that do not interact with Aspirin at the platelet level (Table 1). Interestingly, diclofenac for which its lack of effect on the antiplatelet action of Aspirin has been repeatedly reported appears to diminish the clinical benefit of the latter as reported by 2 of eligible 4 studies (Table 1).

Despite the limited number of eligible studies, meloxicam $(12,16)$ (Table 4) and rofecoxib $(12,13$, 17) (Table 5) do not appear to diminish the cardioprotective effect of Aspirin. This is not unexpected since these drugs do not interact with the anti-platelet properties of Aspirin (Table 1).

The data for celecoxib are not as conclusive as those available for naproxen and even ibuprofen since we found only 3 eligible studies. Two studies that suggest no loss of the beneficial effect of Aspirin $(12,13)$ contradict the other one (17). The reason for the conflicting results is unclear but it may be of relevance to mention that the latter study (17) stands out as the one that has also observed diminishing clinical benefit of Aspirin for ibuprofen, diclofenac as well. Nevertheless, in light of the conflicting data and the limited eligible studies, one cannot draw an unequivocal conclusion as to the clinical outcome of celecoxib-Aspirin interaction. Similarly, one cannot draw a definite conclusion regarding diclofenac as we found only 4 eligible studies, two in each side of the controversy. This is interesting since diclofenac does not interact with Aspirin at the platelet level (Table 1), thus, the loss of cardioprotective effect caused by the drug-drug interaction is unexpected.

Table 4. Reports of concomitant meloxicam/Aspirin use regarding CV risks.

\begin{tabular}{cl}
\hline Reference & \multicolumn{1}{c}{$\begin{array}{c}\text { Beneficial effect of Aspirin in reducing CV risks NOT diminished } \\
\text { (RR/OR/HR (95\% CI)) }\end{array}$} \\
\hline $\mathbf{( 1 2 )}$ & $\begin{array}{l}\text { RR for MI: Aspirin+meloxicam, 0.78 (0.41-1.51); Aspirin alone, } 1.03 \text { (0.95-1.12); meloxicam alone, } 1.61 \\
\text { (1.09-2.40). }\end{array}$ \\
OR for MI: Aspirin+meloxicam, $0.70(0.39,1.25)$; meloxicam alone, 1.41 (1.03-1.92).
\end{tabular}
RR, risk ratio; OR, odds ratio; CV, Cardiovascular; MI, Myocardial Infarction

Table 5. Reports of concomitant rofecoxib/Aspirin use regarding CV risks.

\begin{tabular}{|c|c|}
\hline Reference & $\begin{array}{l}\text { Beneficial effect of Aspirin in reducing CV risks NOT diminished } \\
\text { (RR/OR/HR (95\% CI)) }\end{array}$ \\
\hline (12) & $\begin{array}{l}\text { RR for MI: Aspirin+rofecoxib, RR } 1.51 \text { (0.92-2.47); Aspirin alone, } 1.04 \text { (0.96-1.12); rofecoxib alone, } 1.47 \\
(1.06-2.05) \text {. }\end{array}$ \\
\hline (13) & $\begin{array}{l}\text { RR for MI: no history of MI, Aspirin+rofecoxib, } 1.12(0.88-1.42) \text {; rofecoxib alone, } 1.30 \text { (1.08-1.57); } \\
\text { previous MI, Aspirin+rofecoxib, } 1.50 \text { (1.07-2.09); rofecoxib alone, } 1.75(1.23-2.50) .\end{array}$ \\
\hline (17) & HR for CV: Aspirin+rofecoxib, 1.10 (0.61-1.98); Aspirin alone $0.98(0.94-1.03)$ \\
\hline
\end{tabular}


Table 6. Reports of concomitant celecoxib/Aspirin use regarding CV risks.

\begin{tabular}{|c|c|c|c|}
\hline \multicolumn{2}{|c|}{$\begin{array}{c}\text { Beneficial effect of Aspirin in reducing } \mathrm{CV} \text { risks } \\
\text { NOT diminished }\end{array}$} & \multicolumn{2}{|c|}{$\begin{array}{c}\text { Beneficial effect of Aspirin in reducing CV risks } \\
\text { diminished }\end{array}$} \\
\hline Reference & (RR/OR/HR (95\% CI)) & Reference & (RR/OR/HR (95\% CI)) \\
\hline (12) & $\begin{array}{l}\text { RR for MI: Aspirin+celecoxib, } 1.13(0.63- \\
\text { 2.03); Aspirin alone, } 1.04(0.96-1.12) ; \\
\text { celecoxib alone, } 1.44 \text { (1.04-2.01). } \\
\text { RR for MI: no history of MI, } \\
\text { Aspirin+celecoxib, } 0.88(0.70-1.11) \text {; celecoxib } \\
\text { alone, } 1.11 \text { ( } 0.94-1.32) \text {; previous MI, } 1.27 \\
(0.94-1.71) \text {; celecoxib alone, } 1.59(1.17-2.18) \text {. }\end{array}$ & (17) & $\begin{array}{l}\text { HR for CV: Aspirin+celecoxib, } 1.78 \\
(1.30-2.44) \text {; Aspirin alone, } 0.98 \text { (0.94- } \\
1.03) \text {. }\end{array}$ \\
\hline
\end{tabular}

Table 7. Reports of concomitant diclofenac/Aspirin use regarding CV risks.

\begin{tabular}{|c|c|c|c|}
\hline \multicolumn{2}{|c|}{$\begin{array}{c}\text { Beneficial effect of Aspirin in reducing } \mathrm{CV} \text { risks } \\
\text { NOT diminished }\end{array}$} & \multicolumn{2}{|c|}{$\begin{array}{l}\text { Beneficial effect of Aspirin in reducing CV risks } \\
\text { diminished }\end{array}$} \\
\hline Reference & (RR/OR/HR (95\% CI)) & Reference & (RR/OR/HR (95\% CI)) \\
\hline (19) & $\begin{array}{l}\text { HR for MI: Aspirin+diclofenac: ever exposed, } \\
0.99(0.58-1.76), \geq 30 \text { days: } 0.80(0.54-1.20), \geq \\
60 \text { days, } 1.00(0.61-1.65) \text { vs nonexposed } \\
\text { subjects. }\end{array}$ & (12) & $\begin{array}{l}\text { RR for CV: Aspirin+diclofenac, } 1.41 \\
\text { (1.03-1.93); Aspirin alone, } 1.03(0.96- \\
1.12) \text {; diclofenac alone, } 1.79(1.52-2.12) \text {. }\end{array}$ \\
\hline (23) & $\begin{array}{l}\text { OR for MI: Aspirin+diclofenac, } 1.16(0.82- \\
\text { 1.65) vs Aspirin alone users. }\end{array}$ & (17) & $\begin{array}{l}\text { HR for MI: Aspirin+diclofenac, } 1.74 \\
(1.44-2.08) \text {; Aspirin alone, } 0.98(0.94- \\
1.03) \text {. }\end{array}$ \\
\hline
\end{tabular}

The observation that not all NANSAIDs interact with Aspirin at the clinical level despite the fact that with the exception of meloxicam, rofecoxib and diclofenac, they interact with Aspirin at the platelet level (Table 1) highlights the heterogeneity of NANSAIDs (10) that is often ignored. For, example, Arfè et al. (44) who studied the risk of heart failures causes by NANSAIDs in 4 European countries noticed that only approximately one-half of the drugs used were significantly cardiotoxic. Nevertheless, they calculated the current use of any NANSAIDs, toxic or not, and concluded that the use of any NANSAID was associated with $19 \%$ increased heart failure risk.

The heterogeneity of NANSAIDs is confirmed in a crossover study (30) in which patients received $81 \mathrm{mg}$ of immediate-release Aspirin followed $2 \mathrm{~h}$ later by ibuprofen, rofecoxib, or diclofenac for 6 days. This was followed by a washout period of 14 days, after which the same 2 medications were administered in reverse order for another 6 days. The inhibition of COX-1 was assessed by measuring serum $\mathrm{TxB}_{2}$ level, platelet aggregation induced in platelet-rich plasma and COX-2 activity by the measuring the formation of lipopolysaccharidestimulated PGE2 in whole blood. They noticed no significant interaction between Aspirin and rofecoxib or diclofenac. However, ibuprofen significantly interacted with Aspirin given before or after the NANSAID. The Aspirin-ibuprofen interaction has been confirmed by others $(26-28,31$ 36).

Although we have not made a comparison between molecular interactions studies and clinical trials for all NSAIDs, it is timely to reemphasize that their interaction with Aspirin is heterogeneous in nature. For example, naproxen, celecoxib, piroxicam, indomethacin, mefenamic acid, tiaprofenic acid, nimesulide, oxaprozin, flufenamic acid and dipyrone do interact, while loxoprofen, diclofenac, rofecoxib, etoricoxib, lumiracoxib, etodolac, ketorolac, meloxicam, acetaminophen, flurbiprofen, sulindac, and sodium salicylate do not (Table 8).

It has been suggested that the AspirinNANSAIDs interaction is due to a competition to bind to the Arginine- 120 residue of the COX-1 channel which may prevent the acetylation of the 
serine-529 residue by Aspirin (37, 45). Nevertheless, the interference of NANSAIDs with the anti-platelet effect of Aspirin seems to have no long-term consequences as the $\mathrm{CV}$ protection of Aspirin remains unaffected by concomitant use of, at least, naproxen and ibuprofen. We put forward three plausible explanations for the disconnect between the results of the short-term platelet experiments and those of observational studies. (i) The interaction at the platelet level may be short-lived so that the effect dissipates shortly after its occurrence. (ii) There is no need for near complete inhibition of TxB2 inhibition to benefit from the cardioprotective properties of Aspirin so that despite a reduction in the extent of anti-platelet effect, the beneficial effect persists, or (iii) the CV effect of Aspirin may not be exclusively due to the drug's anti-platelet properties.

For all, except one eligible study, the CV risk was assessed after $>30$ days exposure to the combination while typically, the effect of NANSAIDs on the anti-platelet activity of Aspirin is studied after short exposure times. Thus, the data on the therapeutic outcome of the short-term exposure to Aspirin-NANSAIDs are limited. However, the results published by Kimmel et al. (22) based on a case-control study that assessed the risk only one week before the date of onset of MI are useful in this context. They have reported that addition of NANSAIDs to Aspirin regiment does not increase the CV risk within one week post combination therapy. To this, one may add the fact that, to the best of our knowledge, there is no published report suggestive of a quick negative clinical CV outcome in individual patients who took NANSAIDs therapy while on Aspirin. Furthermore, data from a small size clinical trial, suggest that the effect of naproxen and diclofenac on the Aspirin-induced inhibition of platelet aggregation is short-lived (38). In a randomized placebo-controlled trial, GalliardGrigioni et al. treated healthy subjects with $100 \mathrm{mg}$ aspirin daily in combination with either three doses of either $1 \mathrm{~g}$ acetaminophen, $50 \mathrm{mg}$ diclofenac, 250 $\mathrm{mg}$ naproxen or placebo, and assessed the platelet function. Initially, naproxen enhanced, and diclofenac reduced the anti-aggregatory action of Aspirin while acetaminophen had no effect. After 4 days of treatment, however, the platelet aggregation was equally inhibited by all Aspirin-NANSAID combinations.

In practice, a near complete inhibition of $\mathrm{TxB} 2$, thereby platelet aggregation is aimed to obtain cardioprotective effects of Aspirin (27). This is while the anti-platelet action of Aspirin is shown to be dose-dependent (46), i.e., low doses of the drug may not completely inhibit TxB2. Nevertheless, Aspirin has been shown to be cardioprotective after low doses (Table 9). This may suggest that to benefit from the $\mathrm{CV}$ properties of Aspirin, a complete inhibition of TxB2 is not needed. Thus, a reduced platelet aggregation activity of Aspirin resulted from combination therapies with NANSAIDs, unless proven through appropriately designed clinical trials, may have no significant clinical consequences.

In addition to its anti-platelet effect, Aspirin may reduce $\mathrm{CV}$ risks through other mechanisms. Both inflammation and some NANSAIDs appear to increase CV risks (10). Through animal studies, it has been shown that inflammatory conditions impair the balance of vasodilator/vasoconstrictor components of renin-angiotensin system (RAS) within the heart (47). The RAS is a major regulator of human physiology and has a key role in the CV homeostasis. Interestingly, NANSAIDs appear to be void of significant effects on RAS, instead, they are able to restore the imbalances that are resulted by inflammation (47). Alternatively, an altered protective/toxic balance of the cardioactive CYP450-mediated metabolites of arachidonic acid has been reported to be involved in the cardiotoxic effects of NANSAIDs (48). Whether Aspirin influences the RAS or the CYP450-mediated metabolites of arachidonic acid, remains unknown. Nevertheless, the possibility of CV protection by Aspirin through mechanisms other than its platelet effect is plausible.

The current analysis has limitations some of which are inherent to the nature of included studies. First, we have found that the published clinical evidence was sparse and has substantial limitations. To highlight this point, we were unable to assess the heterogeneity since some studies reported RR/OR while other did HR. Second, the primary outcomes of some studies that we included in our review were not CV (MI or stroke) risks as they reported the latter as secondary outcomes. Last, we were unable to perform meta-analysis as the same reference (Aspirin alone, NANSAID alone or nonusers) or outcome (OR, RR or HR) had not been used across the eligible studies.

\section{CONCLUSION}

Low-dose Aspirin is widely used to prevent MI and other CV diseases. However, there is evidence that concurrent use of some, but not all NANSAIDs, may 
inhibit the anti-platelet effect of Aspirin. Naproxen, meloxicam and rofecoxib do not appear to influence the cardioprotective effect of Aspirin. Similarly, a large body of evidence supports that ibuprofen coadministration with Aspirin does not antagonize the anti-platelet effect of Aspirin. Altogether, it appears that the NANSAID-Aspirin interaction at the level of platelets does not necessarily amount to a loss of beneficial effects of Aspirin. The limited available data suggest that the effect of the drug-drug interactions on the platelet aggregation may dissipate shortly. In addition, it is plausible that the reduced platelet aggregation resulted by the interaction may be sufficient for cardioprotection; i.e., no need for near complete aggregation. In addition, the cardioprotective effect of Aspirin despite reduced platelet aggregation caused by NANSAIDs may be through its involvement in other mechanisms such as the RAS and/or metabolism of arachidonic acid to biologically active compounds mediated by CYP450.

Conflict of interests: The authors have no professional affiliation, financial interest or conflict with the subject matter or information discussed here in this manuscript to declare.

Source of Funding: King Saud University scholarship (Z. Alqahtani) and University of Alberta Self-Directed Grant (F. Jamali).

Authors' contribution: Database search, articles screening, articles review, data analysis, and manuscript preparation: Z. Alqahtani and F. Jamali. Study design and data review: F. Jamali. All authors read and approved the final manuscript.

\section{ACKNOWLEDGMENT}

We thank Janice Kung, a librarian at John W. Scott Health Sciences Library University of Alberta, for her valuable comments.

\section{REFERENCES}

1. Collaborative meta-analysis of randomised trials of antiplatelet therapy for prevention of death, myocardial infarction, and stroke in high risk patients. BMJ. 2002;324:71-86.

2. Meschia JF, Bushnell C, Boden-Albala B, Braun LT, Bravata DM, Chaturvedi S, et al. Guidelines for the Primary Prevention of Stroke. A Statement for Healthcare Professionals From the American Heart

Association/American Stroke Association.
2014;45(12):3754-832.

3. Albers GW, Amarenco P, Easton JD, Sacco RL, Teal P. Antithrombotic and Thrombolytic Therapy for Ischemic Stroke: American College of Chest Physicians Evidence- Based Clinical Practice Guidelines (8th Edition). CHEST. 2008;133(6):630S69S.

4. Jauch EC, Saver JL, Adams HP, Bruno A, Connors JJ, Demaerschalk BM, et al. Guidelines for the Early Management of Patients With Acute Ischemic Stroke. A Guideline for Healthcare Professionals From the American Heart Association/American Stroke Association. 2013;44(3):870-947.

5. Schrör K, Voelker M. NSAIDS and Aspirin: Recent Advances and Implications for Clinical Management. In: Lanas A, editor. NSAIDs and Aspirin: Recent Advances and Implications for Clinical Management. Cham: Springer International Publishing; 2016. p. 107-22.

6. Calatayud S, Esplugues JV. Chemistry, Pharmacodynamics, and Pharmacokinetics of NSAIDs. In: Lanas A, editor. NSAIDs and Aspirin: Recent Advances and Implications for Clinical Management. Cham: Springer International Publishing; 2016. p. 3-16.

7. Reilly I, FitzGerald G. Inhibition of thromboxane formation in vivo and ex vivo: implications for therapy with platelet inhibitory drugs. Blood. 1987;69(1):180-6.

8. Santilli F, Rocca B, De Cristofaro R, Lattanzio S, Pietrangelo L, Habib A, et al. Platelet Cyclooxygenase Inhibition by Low-Dose Aspirin Is Not Reflected Consistently by Platelet Function Assays: Implications for Aspirin "Resistance". Journal of the American College of Cardiology. 2009;53(8):667-77.

9. Panagiotis A K, David F L. The Cardiovascular Toxicity of Selective and Nonselective Cyclooxygenase Inhibitors: Comparisons, Contrasts, and Aspirin Confounding. The Journal of Clinical Pharmacology. 2005;45(7):742-50.

10. Harirforoosh S, Asghar W, Jamali F. Adverse Effects of Nonsteroidal Antiinflammatory Drugs: An Update of Gastrointestinal, Cardiovascular and Renal Complications. J Pharm Pharm Sci 2013;16(5):82147.

11. Hohlfeld T, Saxena A, Schrör K. High on treatment platelet reactivity against aspirin by non-steroidal anti-inflammatory drugs - pharmacological mechanisms and clinical relevance. Thrombosis and Haemostasis 2013;109(5):825-33.

12. García Rodríguez LA, Tacconelli S, Patrignani P. Role of Dose Potency in the Prediction of Risk of Myocardial Infarction Associated With Nonsteroidal Anti-Inflammatory Drugs in the General Population. Journal of the American College of Cardiology. 2008;52(20):1628-36. 
13. Brophy JM, Levesque LE, Zhang B. The coronary risk of cyclo-oxygenase-2 inhibitors in patients with a previous myocardial infarction. Heart. 2007;93(2):189-94.

14. Moher D, Liberati A, Tetzlaff J, Altman DG. Preferred reporting items for systematic reviews and meta-analyses: the PRISMA statement. BMJ. 2009;339:1-8.

15. Andreas S. Critical evaluation of the NewcastleOttawa scale for the assessment of the quality of nonrandomized studies in meta-analyses. European Journal of Epidemiology. 2010(9):603-05.

16. Dalal D, Dubreuil M, Peloquin C, Neogi T, Zhang Y, Choi $\mathrm{H}$, et al. Meloxicam and risk of myocardial infarction: a population-based nested case-control study. Rheumatology International. 2017;37(12):2071-8.

17. Schjerning Olsen A-M, Gislason GH, McGettigan P, Fosbøl E, Sørensen R, Hansen ML, et al. Association of NSAID use with risk of bleeding and cardiovascular events in patients receiving antithrombotic therapy after myocardial infarction. JAMA. 2015;313(8):805-14.

18. van Staa TP, Rietbrock S, Setakis E, Leufkens HGM. Does the varied use of NSAIDs explain the differences in the risk of myocardial infarction? Journal of Internal Medicine. 2008;264(5):481-92.

19. Hudson M, Baron M, Rahme E, Pilote L. Ibuprofen may abrogate the benefits of aspirin when used for secondary prevention of myocardial infarction. The Journal of Rheumatology. 2005;32(8):1589-93.

20. Fischer LM, Schlienger RG, Meier CR, Matter CM, Jick H. Current use of nonsteroidal antiinflammatory drugs and the risk of acute myocardial infarction. Pharmacotherapy. 2005;25(4):503-10.

21. Patel TN, Goldberg KC. Use of aspirin and ibuprofen compared with aspirin alone and the risk of myocardial infarction. Archives of Internal Medicine. 2004;164(8):852-6.

22. Kimmel SE, Berlin JA, Reilly M, Jaskowiak J, Kishel L, Chittams J, et al. The effects of nonselective nonaspirin non-steroidal anti-inflammatory medications on the risk of nonfatal myocardialinfarction and their interaction with aspirin. Journal of the American College of Cardiology. 2004;43(6):985-90.

23. Garcia Rodriguez LA, Varas-Lorenzo C, Maguire A, Gonzalez-Perez A. Nonsteroidal antiinflammatory drugs and the risk of myocardial infarction in the general population. Circulation. 2004;109(24):30006.

24. MacDonald TM, Wei L. Effect of ibuprofen on cardioprotective effect of aspirin. Lancet. 2003;361(9357):573-4.

25. Curtis JP, Wang Y, Portnay EL, Masoudi FA, Havranek EP, Krumholz HM. Aspirin, ibuprofen, and mortality after myocardial infarction: retrospective cohort study. BMJ. 2003;327(7427):1322-3.

26. Yokoyama H, Ito N, Soeda S, Ozaki M, Suzuki Y, Watanabe $\mathrm{M}$, et al. Influence of non-steroidal anti- inflammatory drugs on antiplatelet effect of aspirin. Journal of Clinical Pharmacy \& Therapeutics. 2013;38(1):12-5.

27. Saxena A, Balaramnavar VM, Hohlfeld T, Saxena AK. Drug/drug interaction of common NSAIDs with antiplatelet effect of aspirin in human platelets. European Journal of Pharmacology. 2013;721(13):215-24.

28. Shibata K, Akagi $\mathrm{Y}$, Nozawa N, Shimomura H, Aoyama T. Influence of nonsteroidal antiinflammatory drugs on aspirin's antiplatelet effects and suggestion of the most suitable time for administration of both agents without resulting in interaction. Journal of Pharmaceutical Health Care \& Sciences. 2017;3(9):1-10.

29. Cryer B, Berlin R, Cooper S, Hsu C, Wason S. Double-blind, randomized, parallel, placebocontrolled study of ibuprofen effects on thromboxane B2 concentrations in aspirin-treated healthy adult volunteers. Clinical therapeutics. 2005;27(2):185-91.

30. Catella-Lawson F, Reilly MP, Kapoor SC, Cucchiara AJ, DeMarco S, Tournier B, et al. Cyclooxygenase inhibitors and the antiplatelet effects of aspirin. New England Journal of Medicine. 2001;345(25):1809-17.

31. Schuijt MP, Huntjens-Fleuren HW, de Metz M, Vollaard EJ. The interaction of ibuprofen and diclofenac with aspirin in healthy volunteers. British Journal of Pharmacology. 2009;157(6):931-4.

32. Renda G, Tacconelli S, Capone ML, Sacchetta D, Santarelli F, Sciulli MG, et al. Celecoxib, ibuprofen, and the antiplatelet effect of aspirin in patients with osteoarthritis and ischemic heart disease. Clinical Pharmacology and Therapeutics. 2006;80(3):264-74.

33. Gengo FM, Rubin L, Robson M, Rainka M, Gengo MF, Mager DE, et al. Effects of Ibuprofen on the Magnitude and Duration of Aspirin's Inhibition of Platelet Aggregation: Clinical Consequences in Stroke Prophylaxis. Journal of Clinical Pharmacology. 2008;48(1):117-22.

34. Li X, Fries S, Li R, Lawson JA, Propert KJ, Diamond $\mathrm{SL}$, et al. Differential impairment of aspirindependent platelet cyclooxygenase acetylation by nonsteroidal antiinflammatory drugs. Proceedings of the National Academy of Sciences of the United States of America. 2014;111(47):16830-5.

35. Gladding PA, Webster MW, Farrell HB, Zeng IS, Park R, Ruijne N. The antiplatelet effect of six nonsteroidal anti-inflammatory drugs and their pharmacodynamic interaction with aspirin in healthy volunteers. American Journal of Cardiology. 2008;101(7):1060-3.

36. Meek IL, Vonkeman HE, Kasemier J, Movig KLL, van de Laar M. Interference of NSAIDs with the thrombocyte inhibitory effect of aspirin: A placebocontrolled, ex vivo, serial placebo-controlled serial crossover study. European Journal of Clinical Pharmacology. 2013;69(3):365-71.

37. Capone ML, Sciulli MG, Tacconelli S, Grana M, Ricciotti E, Renda G, et al. Pharmacodynamic 
interaction of naproxen with low-dose aspirin in healthy subjects. Journal of the American College of Cardiology. 2005;45(8):1295-301.

38. Galliard-Grigioni KS, Reinhart WH. A randomized, controlled study on the influence of acetaminophen, diclofenac, or naproxen on aspirin-induced inhibition of platelet aggregation. European Journal of Pharmacology. 2009;609(1-3):96-9.

39. Anzellotti P, Capone ML, Jeyam A, Tacconelli S, Bruno A, Tontodonati $\mathrm{P}$, et al. Low-dose naproxen interferes with the antiplatelet effects of aspirin in healthy subjects: recommendations to minimize the functional consequences. Arthritis \& Rheumatism. 2011;63(3):850-9.

40. Wilner KD, Rushing M, Walden C, Adler R, Eskra J, Noveck R, et al. Celecoxib does not affect the antiplatelet activity of aspirin in healthy volunteers. Journal of Clinical Pharmacology. 2002;42(9):102730.

41. Ruzov M, Rimon G, Pikovsky O, Stepensky D. Celecoxib interferes to a limited extent with aspirinmediated inhibition of platelets aggregation. British Journal of Clinical Pharmacology. 2016;81(2):31626.

42. Greenberg HE, Gottesdiener K, Huntington M, Wong $\mathrm{P}$, Larson $\mathrm{P}$, Wildonger $\mathrm{L}$, et al. A new cyclooxygenase-2 inhibitor, rofecoxib (VIOXX), did not alter the antiplatelet effects of low-dose aspirin in healthy volunteers. Journal of Clinical Pharmacology. 2000;40(12 Pt 2):1509-15.

43. van Ryn J, Kink-Eiband M, Kuritsch I, Feifel U, Hanft G, Wallenstein G, et al. Meloxicam does not affect the antiplatelet effect of aspirin in healthy male and female volunteers. Journal of Clinical Pharmacology. 2004;44(7):777-84.
44. Arfè A, Scotti L, Varas-Lorenzo C, Nicotra F, Zambon A, Kollhorst B, et al. Non-steroidal antiinflammatory drugs and risk of heart failure in four European countries: nested case-control study. BMJ. 2016;354(4857).

45. Russo NW, Petrucci G, Rocca B. Aspirin, stroke and drug-drug interactions. Vascular Pharmacology. 2016;87(Supplement C):14-22.

46. Warner TD, Nylander S, Whatling C. Anti-platelet therapy: cyclo-oxygenase inhibition and the use of aspirin with particular regard to dual anti-platelet therapy. British Journal of Clinical Pharmacology. 2011;72(4):619-33.

47. Asghar W, Aghazadeh-Habashi A, Jamali F. Cardiovascular effect of inflammation and nonsteroidal anti-inflammatory drugs on reninangiotensin system in experimental arthritis. Inflammopharmacology. 2017;25(5):543-53.

48. Aghazadeh-Habashi A, Asghar W, Jamali F. DrugDisease Interaction: Effect of Inflammation and Nonsteroidal Anti-Inflammatory Drugs on Cytochrome P450 Metabolites of Arachidonic Acid. Journal of Pharmaceutical Sciences. 2017;107(2):756-63.

49. Jermany J, Branson J, Schmouder R, Guillaume M, Rordorf C. Lumiracoxib does not affect the ex vivo antiplatelet aggregation activity of low-dose aspirin in healthy subjects. Journal of Clinical Pharmacology. 2005;45(10):1172-8.

50. Dahl ML, Uotila P. Salicylate does not interfere with aspirin in human blood in vivo. Prostaglandins Leukotrienes and Medicine. 1984;13(2):169-70. 


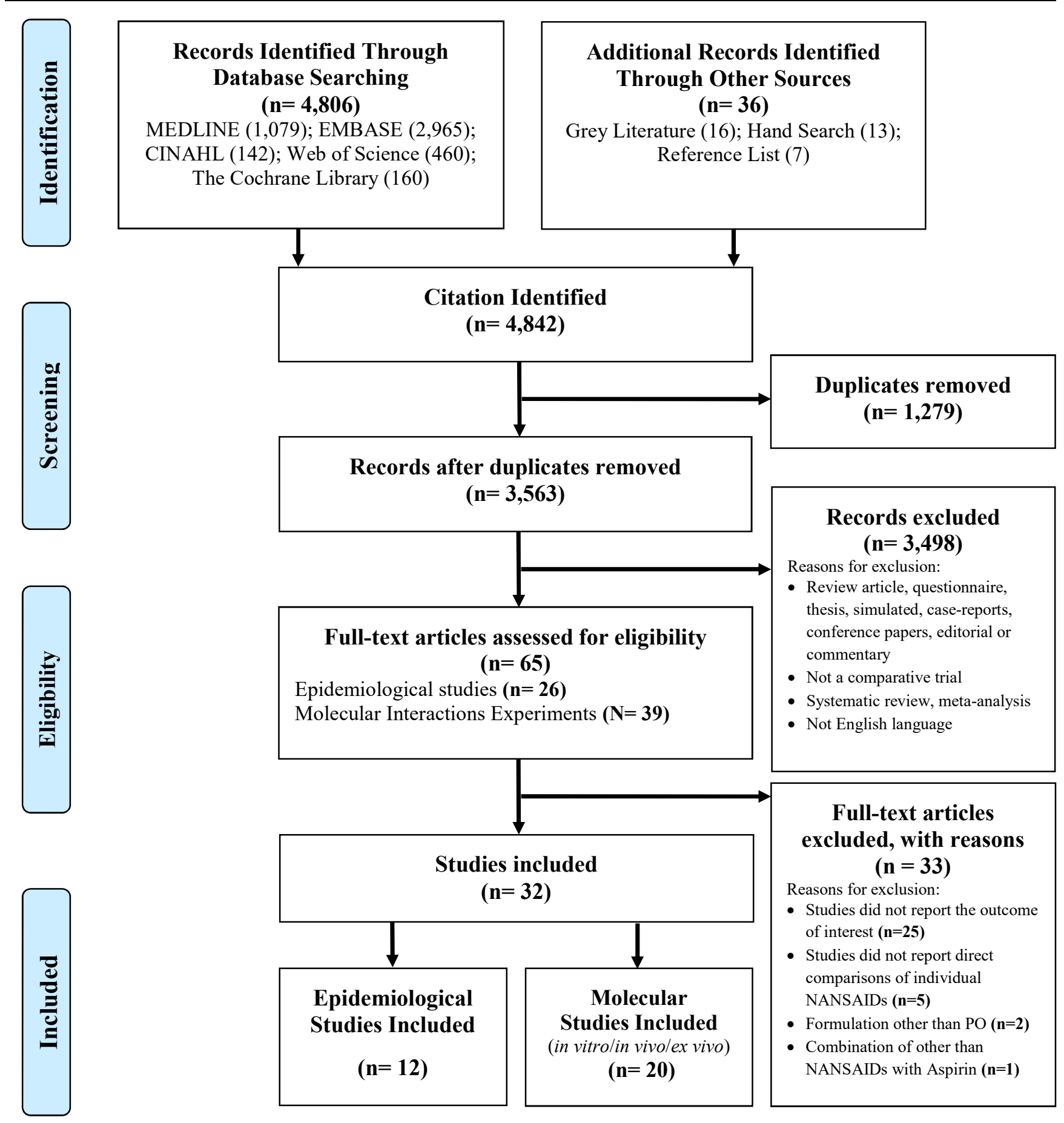

Figure 1. PRISMA (14) flow chart of study selection 
Table 8. Main characteristics of the included molecular interactions studies that reported the influence of NANSAIDs on the anti-platelet action of Aspirin in human blood samples (in vitro), healthy volunteers (in vivo) or isolated platelets (ex vivo) studies.

\begin{tabular}{|c|c|c|c|c|c|c|}
\hline Reference & Year & $\begin{array}{l}\text { Type of } \\
\text { study } \\
\text { (species) }\end{array}$ & Subjects & Treatments & Analyzed parameters & Conclusions \\
\hline (28) & 2017 & $\begin{array}{l}\text { in vitro } \\
\text { (human) }\end{array}$ & $\begin{array}{l}\text { Healthy volunteers } \\
\qquad(n=6)\end{array}$ & $\begin{array}{l}\text { Aspirin only, ibuprofen (6 min after Aspirin) } \\
\text { or loxoprofen ( } 6 \text { min after Aspirin) plus } \\
\text { Aspirin groups were added to PRP. }\end{array}$ & $\begin{array}{l}\text { Platelet aggregation by } \\
\text { aggregometry and serum } \\
\mathrm{TxB}_{2} \text { levels }\end{array}$ & $\begin{array}{l}\text { Ibuprofen interferes with the } \\
\text { anti-platelet effect of low-dose } \\
\text { Aspirin; however, loxoprofen } \\
\text { do not when given 6-12 h } \\
\text { before Aspirin. }\end{array}$ \\
\hline (26) & 2013 & $\begin{array}{l}\text { in vitro } \\
\text { (human) }\end{array}$ & $\begin{array}{l}\text { Healthy volunteers } \\
\qquad(n=6)\end{array}$ & $\begin{array}{l}\text { Aspirin, ibuprofen, loxoprofen, } \\
\text { indomethacin, diclofenac, etodolac, } \\
\text { mefenamic acid, naproxen, meloxicam, or } \\
\text { flurbiprofen were added alone to PRP, then } \\
\text { Aspirin was added before and after each } \\
\text { NANSAID to PRP. }\end{array}$ & $\begin{array}{l}\text { Platelet aggregation by } \\
\text { aggregometry }\end{array}$ & $\begin{array}{l}\text { Only ibuprofen and mefenamic } \\
\text { acid significantly interfere } \\
\text { with the anti-platelet effect of } \\
\text { Aspirin when taken after. }\end{array}$ \\
\hline (27) & 2013 & $\begin{array}{l}\text { in vitro } \\
\text { (human) }\end{array}$ & $\begin{array}{l}\text { Healthy volunteers } \\
\qquad(n=7)\end{array}$ & $\begin{array}{l}\text { Ibuprofen, naproxen, diclofenac, ketorolac, } \\
\text { flufenamate, piroxicam, dipyrone, } \\
\text { celecoxib, nimesulide, acetaminophen or } \\
\text { oxaprozin were added alone or together } \\
\text { with Aspirin to PRP. }\end{array}$ & $\begin{array}{l}\text { Platelet aggregation } \\
\text { (induced by AA), plasma } \\
\mathrm{TxB}_{2} \text { concentrations by } \\
\text { aggregometry }\end{array}$ & $\begin{array}{l}\text { Celecoxib, dipyrone, ibuprofen, } \\
\text { flufenamic acid, naproxen, } \\
\text { nimesulide, oxaprozin, and } \\
\text { piroxicam significantly } \\
\text { interfere with the anti-platelet } \\
\text { activity of Aspirin. While } \\
\text { diclofenac, ketorolac and } \\
\text { acetaminophen do not. }\end{array}$ \\
\hline (37) & 2005 & $\begin{array}{l}\text { in vitro, } \\
\text { in vivo } \\
\text { and ex } \\
\text { vivo } \\
\text { (human) }\end{array}$ & $\begin{array}{l}\text { Healthy volunteers } \\
\text { (aged 23-30 years, } \\
\qquad n=4 \text { ) }\end{array}$ & $\begin{array}{l}\text { The volunteers received Aspirin ( } 100 \mathrm{mg} \text {, } \\
\text { once daily) for } 6 \text { days. Then they received } \\
\text { either single or multiple doses of the } \\
\text { combination of Aspirin } 2 \mathrm{~h} \text { before } \\
\text { naproxen ( } 500 \mathrm{mg} \text {, twice daily) for another } \\
6 \text { days. After a washout period of } 14 \text { days, } \\
\text { the treatments were administered in reverse } \\
\text { order. }\end{array}$ & $\begin{array}{l}\text { Serum } \mathrm{TxB}_{2} \text {, urinary } 11 \\
\text { dehydro-TxB excretion } \\
\text { rates, platelet aggregation } \\
\text { by aggregometry, LPS- } \\
\text { stimulated } \text { PGE }_{2} \\
\text { production in whole } \\
\text { blood }\end{array}$ & $\begin{array}{l}\text { Naproxen interferes with the } \\
\text { inhibitory effect of low-dose } \\
\text { Aspirin on platelet } \\
\text { aggregation. }\end{array}$ \\
\hline (41) & 2016 & $\begin{array}{l}\text { in vivo } \\
\text { (human) }\end{array}$ & $\begin{array}{l}\text { Healthy volunteers } \\
\text { (aged 18-50 years) }\end{array}$ & $\begin{array}{l}\text { Aspirin and celecoxib (alone or together) or } \\
\text { control (saline) were added to the PRP. }\end{array}$ & $\begin{array}{l}\text { Platelet aggregation } \\
\text { (induced by AA) by } \\
\text { aggregometry }\end{array}$ & $\begin{array}{l}\text { Celecoxib interferes to a limited } \\
\text { extent with the anti-platelet } \\
\text { effect of low-dose Aspirin. }\end{array}$ \\
\hline
\end{tabular}


TABLE 8. Continued...

\begin{tabular}{|c|c|c|c|c|c|}
\hline (34) & 2014 & $\begin{array}{l}\text { ex vivo } \\
\text { (human) }\end{array}$ & $\begin{array}{l}\text { Healthy volunteers } \\
\qquad(n=5)\end{array}$ & $\begin{array}{l}\text { Platelets were pre-incubated with ibuprofen, } \\
\text { naproxen, or celecoxib for } 10 \mathrm{~min} \text {. then } \\
\text { Aspirin was added to each group. }\end{array}$ & $\begin{array}{l}\mathrm{COX}-1 \text { acetylation, } \mathrm{TxB}_{2} \\
\text { formation }\end{array}$ \\
\hline (34) & 2014 & $\begin{array}{l}\text { in vivo } \\
\text { (human) }\end{array}$ & $\begin{array}{l}\text { Healthy volunteers } \\
\qquad(n=7)\end{array}$ & $\begin{array}{l}\text { Subjects received a single dose of ibuprofen } \\
(600 \mathrm{mg}) \text {, naproxen ( } 500 \mathrm{mg}) \text {, or celecoxib } \\
(200 \mathrm{mg}) \text {, then a single dose of Aspirin } \\
(325 \mathrm{mg}) \text { was given } 2 \mathrm{~h} \text { after the } \\
\text { NANSAID. }\end{array}$ & $\begin{array}{l}\text { COX-1 acetylation, } \\
\text { platelet aggregation } \\
\text { (induced by AA), platelet } \\
\mathrm{TxB}_{2} \text {, urinary } 11 \text {-dehydro } \\
\mathrm{TxB}_{2}\end{array}$ \\
\hline (36) & 2013 & $\begin{array}{l}\text { ex vivo } \\
\text { (human) }\end{array}$ & $\begin{array}{l}\text { Healthy volunteers } \\
\qquad(n=30)\end{array}$ & $\begin{array}{l}\text { The Volunteers were randomly allocated in } \\
\text { two groups. First group received two daily } \\
\text { doses of naproxen ( } 500 \mathrm{mg}) \text {, ibuprofen } \\
(600 \mathrm{mg}) \text { or placebo. Second group } \\
\text { received one daily dose of meloxicam ( } 15 \\
\mathrm{mg}) \text {, etoricoxib ( } 90 \mathrm{mg}) \text { or placebo. Both } \\
\text { groups received Aspirin ( } 80 \mathrm{mg}) 2 \mathrm{~h} \text { after } \\
\text { 2nd or 3rd dose of study medication. }\end{array}$ & $\begin{array}{l}\text { ex vivo thrombocyte } \\
\text { function, CT (seconds) } \\
\text { was measured using the } \\
\text { PFA-100 CT }\end{array}$ \\
\hline (39) & 2011 & $\begin{array}{l}\text { in vivo } \\
\text { and } \\
\text { ex vivo } \\
\text { (human) }\end{array}$ & $\begin{array}{l}\text { Healthy volunteers } \\
\text { (aged 23-37 years, } \\
\quad n=9 \text { ) }\end{array}$ & $\begin{array}{l}\text { Subjects received either a combination of } \\
\text { Aspirin }(100 \mathrm{mg}) 2 \mathrm{~h} \text { before or after } \\
\text { naproxen }(220 \mathrm{mg} \text {, twice a day), or Aspirin } \\
\text { alone for } 6 \text { days separated by } 14 \text { days of } \\
\text { washout. }\end{array}$ & $\begin{array}{l}\text { Serum } \mathrm{TxB}_{2} \text { and platelet } \\
\text { aggregation (induced by } \\
\text { AA and collagen) }\end{array}$ \\
\hline (31) & 2009 & $\begin{array}{l}\text { in vivo } \\
\text { (human) }\end{array}$ & $\begin{array}{l}\text { Healthy volunteers } \\
\text { (aged 26-58 years, } \\
\quad n=12 \text { ) }\end{array}$ & $\begin{array}{l}\text { The volunteers were randomly assigned to } \\
\text { either Aspirin ( } 30 \mathrm{mg} \text {, once daily) for } 7 \\
\text { days, slow release diclofenac ( } 50 \mathrm{mg} \text {, three } \\
\text { times daily) or ibuprofen ( } 800 \mathrm{mg} \text {, three } \\
\text { times daily) for } 1 \text { day. Aspirin ( } 80 \mathrm{mg} \text {, } \\
\text { once daily) was given after a washout } \\
\text { period of } 14-42 \text { days with each treatment } \\
\text { group for } 7 \text { days. }\end{array}$ & Serum $\mathrm{TxB}_{2}$ levels \\
\hline
\end{tabular}

A single therapeutic dose of ibuprofen or naproxen followed by Aspirin casue a potent drug-drug interaction, but not between celecoxib and Aspirin.

Ibuprofen and naproxen interfere with anti-platelet effect of Aspirin, but etoricoxib and meloxicam do not.

Naproxen interferes with the anti-platelet activity of Aspirin. The interaction was similar when naproxen giving $2 \mathrm{~h}$ before or after low-dose of Aspirin.

Only ibuprofen interferes with the anti-platelet activity of Aspirin. 


\section{TABLE 8. Continued..}

\begin{tabular}{|c|c|c|c|}
\hline (38) & 2009 & $\begin{array}{l}\text { ex vivo } \\
\text { (human) }\end{array}$ & $\begin{array}{l}\text { Healthy volunteers } \\
\text { (aged 21-58 years, } \\
\quad n=11 \text { ) }\end{array}$ \\
\hline
\end{tabular}

$$
2008 \quad \begin{gathered}
\text { ex vivo } \\
\text { (human) }
\end{gathered} \quad \begin{gathered}
\text { Healthy volunteers } \\
(n=24)
\end{gathered}
$$
2008 in vivo Healthy volunteers (human) (aged 21-32 years,

$$
n=10)
$$

Osteoarthritis and stable ischaemic

ex vivo heart disease patients

(human) (aged 45-73 years,

$$
n=29 \text { ) }
$$

The volunteers received during 4 different study periods ( $\geq 10$ days washout period) either acetaminophen $(1 \mathrm{~g}$, three times daily), diclofenac (50 mg, three times daily), naproxen (250 mg, three times daily) or placebo plus Aspirin (100 mg, once daily) for 4 days.

The volunteers received randomly either naproxen (550 mg), ibuprofen (400 mg), celecoxib (200 mg), indomethacin $(25 \mathrm{mg})$, tiaprofenic acid SR (300 mg) or sulindac (200 mg), Aspirin (300 mg) or placebo for 2 days.

The volunteers were randomly assigned to receive either ibuprofen (400 mg), Aspirin (325 mg) or ibuprofen (400 mg) plus one dose of Aspirin (325 mg, 2 h later). A minimum of 6 days washout period was allowed between treatments.

\section{The patients were undergoing long term} treatment with Aspirin (100 mg, daily), and received celecoxib (200 mg, twice daily), ibuprofen (600 mg, three times daily) or placebo for 7 days.

The volunteers were randomly assigned to receive either lumiracoxib (400 mg, once daily) or placebo for 11 days. Both treatment groups received Aspirin (75mg, once daily) from day 5 to 11 (6 days).

The volunteers received Aspirin (81 mg, once daily) for 8 days. On day 9 , subjects received either ibuprofen $(400 \mathrm{mg}$, three times daily) or placebo (three times daily) for 10 days.
PFA-100 CT

PFA-100 CT

Platelet aggregation by aggregometry

Serum $\mathrm{TxB}_{2}$, urinary 11 dehydro- $\mathrm{TxB}_{2}$ excretion rates, platelet aggregation by aggregometry, LPSstimulated $\mathrm{PGE}_{2}$

production in whole blood

Platelet aggregation (induced by AA and collagen), Serum $\mathrm{TxB}_{2}$ levels, urinary $\mathrm{TxB}_{2}$ and prostacyclin excretion rate

Serum $\mathrm{TxB}_{2}$ levels
Regular daily co-administration of acetaminophen, diclofenac or naproxen do not interfere with the anti-platelet activity of Aspirin.

Ibuprofen, indomethacin, naproxen, and tiaprofenic acid interfere with the anti-platelet activity of Aspirin but not sulindac or celecoxib.

Administration of ibuprofen before Aspirin interferes with the inhibitory effect of Aspirin on platelet aggregation.

Ibuprofen interferes with antiplatelet effect of Aspirin but not celecoxib.

Lumiracoxib does not interfere with anti-platelet effect of low-dose Aspirin.

No clinically meaningful loss of cardioprotection was found in healthy volunteers who received OTC doses of ibuprofen with low-dose Aspirin. 
TABLE 8. Continued...

(43) $2004 \begin{gathered}\text { in vivo } \\ \text { (human) }\end{gathered} \quad \begin{gathered}\text { Healthy volunteers } \\ \text { (aged 20-47 years, } \\ 55-87 \mathrm{~kg}, n=16)\end{gathered}$

(40)

$$
\begin{array}{ccc}
2002 & \begin{array}{c}
\text { in vivo } \\
\text { (human) }
\end{array} & \begin{array}{c}
\text { Healthy volunteers } \\
\text { (aged 18-48 years, } \\
48.7-86 \mathrm{~kg}, n=17)
\end{array} \\
2001 \quad \begin{array}{c}
\text { ex vivo } \\
\text { (human) }
\end{array} & \begin{array}{c}
\text { Healthy volunteers } \\
\text { (aged } 18-65 \text { years, } \\
n=12)
\end{array}
\end{array}
$$

$$
2001 \quad \begin{gathered}
\text { ex vivo } \\
\text { (human) }
\end{gathered} \quad \begin{gathered}
\text { Healthy volunteers } \\
\text { (aged 18-65 years, } \\
n=10)
\end{gathered}
$$

$2000 \quad$ ex vivo

(human)

Healthy volunteers (aged 18-38 years,

$$
45.2-103.7 \mathrm{~kg} \text {, }
$$$$
n=24)
$$

$$
1984 \begin{gathered}
\text { in vivo } \\
\text { (human) }
\end{gathered} \quad \begin{gathered}
\text { Healthy volunteers } \\
\text { (aged 22-32 years, } \\
n=6)
\end{gathered}
$$

The volunteers received meloxicam (15 mg, once daily) alone for 4 days, then Aspirin (100 mg, once daily $2 \mathrm{~h}$ later) was added for another 6 days. After a washout period of 14 days, subjects received only Aspirin (100 mg, once daily) for 2 days.

The volunteers received celecoxib (200 mg, twice daily) or placebo for 4 days. On day 5 , all volunteers received Aspirin $(325 \mathrm{mg}$ ) with either celecoxib (20 mg) or placebo.

The volunteers received Aspirin $(81 \mathrm{mg}) 2 \mathrm{~h}$ before single dose of either ibuprofen (400 $\mathrm{mg})$, acetaminophen (1000 mg), or rofecoxib (25 mg) for 6 days. After a washout period of 14 days, the same medications were given in the reverse order for 6 days.

The volunteers received Aspirin (81 mg) $2 \mathrm{~h}$ before single dose of either ibuprofen (400 $\mathrm{mg}$, three times daily) or delayed-release diclofenac (75 mg, twice daily) for 6 days.

The volunteers received either rofecoxib (50 $\mathrm{mg}$, once daily) or placebo for 10 days and Aspirin (81 mg, once daily) for 7 days (days 4-10).

\section{The volunteers received sodium salicylate (1500 mg) and, $1 \mathrm{~h}$ later, Aspirin (500 mg).} After 2 weeks, subjects received only Aspirin (500 mg)
Platelet aggregation by aggregometry, serum $\mathrm{TxB}_{2}$

Serum $\mathrm{TxB}_{2}$ levels, platelet aggregation (induced by ADP, AA and collagen) Serum $\mathrm{TxB}_{2}$, platelet aggregation (induced by AA in PRP), LPSstimulated $\mathrm{PGE}_{2}$ production in whole blood, prostaglandin $\mathrm{I}_{2}$

Serum $\mathrm{TxB}_{2}$, platelet aggregation by aggregometry

\section{Serum $\mathrm{TxB}_{2}$, platelet} aggregation by aggregometry

Meloxicam does not interfere with the inhibitory effect of low-dose Aspirin on platelet aggregation.

Celecoxib does not interfere with anti-platelet effect of Aspirin.

Only ibuprofen interferes with anti-platelet effect of Aspirin.

Rofecoxib does not interfere with the inhibitory effect of low-dose Aspirin on platelet aggregation.

Serum $\mathrm{TxB}_{2}$

concentrations
Sodium salicylate does not interfere with the inhibitory effect of Aspirin.

PRP, Platelet Rich Plasma; AA, arachidonic acid; $\mathrm{TxB}_{2}$, thromboxane $\mathrm{B}_{2}$; PFA, platelet function analyzer; $\mathrm{PGE}_{2}$, prostaglandin $\mathrm{E}_{2}$; LPS, lipopolysaccharide; COX-1, cyclooxygenase-1; h, hours; CT, closure time; OTC, over the counter; ADP, adenosine 5'-diphosphate. 
Table 9. Main characteristics of the included epidemiological studies.

\begin{tabular}{|c|c|c|c|c|c|c|c|c|c|}
\hline Reference & Year & Country & $\begin{array}{l}\text { Type of } \\
\text { study }\end{array}$ & $\begin{array}{l}\text { Participants } \\
(\text { events, } n)\end{array}$ & Duration & $\begin{array}{l}\mathrm{F} \% \text {, age (yr), history of } \mathrm{CV} / \text { stroke } \\
\text { events, } \\
\text { Aspirin use, NANSAIDs use }\end{array}$ & Comparison, $n$ & Outcomes & $\begin{array}{l}\text { Quality } \\
\text { Assessment } \\
\text { (NOS) }\end{array}$ \\
\hline (17) & 2015 & Denmark & Cohort & $\begin{array}{l}61,971 \\
\text { patients } \\
(\mathrm{CV} \\
18,568)\end{array}$ & $3.5 \mathrm{yr}$ & $\begin{array}{l}36.8 \%, 67.7(\mathrm{SD}, 13.6) \mathrm{yr}, 4.9 \%, \\
18.0 \%, \\
\text { rofecoxib } 0.8 \%, \\
\text { celecoxib } 1.2 \%, \\
\text { diclofenac } 9.9 \%, \\
\text { ibuprofen } 23.1 \% \text {, } \\
\text { naproxen } 1.7 \% \text {, } \\
\text { other } 6.6 \%\end{array}$ & $\begin{array}{l}\text { Overall } \\
\text { NANSAID use, } \\
9,194\end{array}$ & $\begin{array}{l}\text { Primary: } \\
\text { Admission or } \\
\text { death of GI } \\
\text { bleeding } \\
\text { Secondary: CV } \\
\text { death, nonfatal } \\
\text { recurrent MI, } \\
\text { and ischemic } \\
\text { stroke, transient } \\
\text { ischemic attack, } \\
\text { or systemic } \\
\text { arterial emboli }\end{array}$ & $\begin{array}{l}\text { Selection: } \\
4 \text { stars; } \\
\text { comparability: } \\
2 \text { stars; exposure: } \\
2 \text { stars }\end{array}$ \\
\hline (18) & 2008 & UK & Cohort & $\begin{array}{c}\text { 729,294 } \\
\text { NSAID } \\
\text { users: } \\
443,047 \\
\text { controls } \\
\text { (MI, 5,690) }\end{array}$ & $6.1: 5.6 \mathrm{yr}$ & $\begin{array}{l}54.1 \%, 58.0 \mathrm{yr}: 58.2 \mathrm{yr}, \\
7.4 \% / 3.1 \%: 6.9 \% / 3.4 \%, 76.2 \% \text {, } \\
\text { ibuprofen } 31.1 \% \text {, } \\
\text { diclofenac } 39.6 \% \text {, } \\
\text { naproxen } 9.1 \% \text {, } \\
\text { meloxicam } 3.8 \% \text {, indomethacin } \\
3.6 \% \text {, piroxicam } 2.0 \% \text {, } \\
\text { mefenamic acid } 1.9 \%\end{array}$ & $\begin{array}{l}\text { Control cohort } \\
\text { (matched by } \\
\text { disease } \\
\text { risk score), } \\
443,047\end{array}$ & MI & $\begin{array}{l}\text { Selection: } \\
4 \text { stars; } \\
\text { comparability: } \\
2 \text { stars; exposure: } \\
2 \text { stars }\end{array}$ \\
\hline (19) & 2005 & Canada & Cohort & $\begin{array}{c}18,503 \\
\text { patients } \\
(\mathrm{AMI}, 535)\end{array}$ & 239.7 days & $\begin{array}{l}42.3 \%: 45.1 \%, 74 \mathrm{yr}, 23.0 \% / 6.5 \% \text { : } \\
18.9 \% / 5.6 \% \text {, NA, ibuprofen } \\
9.1 \% \text {, naproxen } 30.4 \% \text {, diclofenac } \\
36.1 \%\end{array}$ & $\begin{array}{l}\text { Unexposed, } \\
14,424\end{array}$ & AMI & $\begin{array}{l}\text { Selection: } \\
4 \text { stars; } \\
\text { Comparability: } \\
2 \text { stars; Exposure: } \\
3 \text { stars }\end{array}$ \\
\hline (24) & 2003 & UK & Cohort & $\begin{array}{c}7,107 \\
\text { patients } \\
\text { (mortality, } \\
3,813)\end{array}$ & $3.3 \mathrm{yr}$ & $\begin{array}{l}\text { NA, } 27-100 \text { yr, } 50.5 \% / 23.8 \% \text {, } \\
100 \% \text {, ibuprofen } 187 \text {, diclofenac } \\
206 \text {, other } 429\end{array}$ & Unexposed, 6,285 & $\begin{array}{l}\text { All-cause } \\
\text { mortality or CV } \\
\text { mortality }\end{array}$ & $\begin{array}{l}\text { Selection: } \\
4 \text { stars; } \\
\text { Comparability: } \\
2 \text { stars; } \\
\text { Exposure: } \\
2 \text { stars }\end{array}$ \\
\hline
\end{tabular}


TABLE 9. Continued...

\begin{tabular}{|c|c|c|c|c|c|c|c|c|c|}
\hline (25) & 2003 & USA & Cohort & $\begin{array}{c}70,316 \\
\text { patients } \\
\text { (mortality, } \\
12,096)\end{array}$ & $3 \mathrm{yr}$ & $\begin{array}{l}48.3 \%, 75 \text { yr }(53.9 \%), \\
30.5 \% / 13.2 \%, 96.1 \%(66,739), \\
\text { ibuprofen } 844 \text {, other } 2,733\end{array}$ & $\begin{array}{l}\text { Unexposed, } \\
66,739\end{array}$ & $\begin{array}{l}\text { Mortality within } \\
1 \text { year after } \\
\text { discharge }\end{array}$ & $\begin{array}{l}\text { Selection: } \\
4 \text { stars; } \\
\text { Comparability: } \\
2 \text { stars; } \\
\text { Exposure: } \\
2 \text { stars }\end{array}$ \\
\hline (16) & 2017 & UK & $\begin{array}{l}\text { Case- } \\
\text { control }\end{array}$ & $\begin{array}{l}\text { 9,291 cases: } \\
30,676 \\
\text { controls } \\
\text { (MI, 9,291) }\end{array}$ & $13 \mathrm{yr}$ & $\begin{array}{l}41.7 \%: 43.1 \%, 67.4 \mathrm{yr}( \pm 11.9) \text { : } \\
66.3 \mathrm{yr}( \pm 11.6), 24.7 \%: 9.9 \% \text {, } \\
34.6 \%: 21.0 \% \text {, } \\
\text { diclofenac } 1,020: 2,846 \text {, } \\
\text { meloxicam } 248: 655, \text { naproxen } \\
\text { 277: } 886, \text { other } 1,246: 3,843\end{array}$ & $\begin{array}{l}\text { Remote users (no } \\
\text { exposure }>60 \\
\text { days prior index } \\
\text { date but within } 1 \\
\text { year), } \\
4,184: 15,488\end{array}$ & MI & $\begin{array}{l}\text { Selection: } \\
3 \text { stars; } \\
\text { comparability: } \\
2 \text { stars; exposure: } \\
2 \text { stars }\end{array}$ \\
\hline (12) & 2008 & UK & $\begin{array}{l}\text { Case- } \\
\text { control }\end{array}$ & $\begin{array}{l}8,852 \text { cases: } \\
20,000 \\
\text { controls } \\
(\mathrm{MI}, 8,852)\end{array}$ & $4.1 \mathrm{yr}$ & $\begin{array}{l}\text { NA, 50-84 yr, NA, NA, celecoxib } \\
81: 144 \text {, } \\
\text { diclofenac } 353: 483 \text {, ibuprofen } \\
\text { 143:314, indomethacin } 29: 45, \\
\text { meloxicam 59:99, } \\
\text { naproxen 54:119, } \\
\text { refecoxib 98:139 }\end{array}$ & $\begin{array}{l}\text { Control cohort } \\
\text { (matched by sex, } \\
\text { age within } 1 \text { year, } \\
\text { and calendar } \\
\text { year), } 20,000\end{array}$ & MI & $\begin{array}{l}\text { Selection: } \\
4 \text { stars; } \\
\text { Comparability: } \\
2 \text { stars; } \\
\text { Exposure: } \\
2 \text { stars }\end{array}$ \\
\hline (13) & 2007 & Canada & $\begin{array}{l}\text { Case- } \\
\text { control }\end{array}$ & $\begin{array}{l}3,423 \text { cases: } \\
68,456 \\
\text { controls } \\
(\mathrm{MI}, 3,423)\end{array}$ & $2.3 \mathrm{yr}$ & $\begin{array}{l}52.1 \%: 67.1 \%, 78.2 \text { yr }(5.4) \\
16.9 \% / 2.0 \%: 6.2 \% / 0.9 \% \\
35.7 \%: 21.8 \%, 71.4 \%\end{array}$ & $\begin{array}{l}\text { Control cohort } \\
\text { (matched by sex, } \\
\text { age within } 1 \text { year, } \\
\text { and calendar } \\
\text { year), } 68,456\end{array}$ & $\begin{array}{l}\text { Nonfatal or fatal } \\
\text { MI }\end{array}$ & $\begin{array}{l}\text { Selection: } \\
3 \text { stars; } \\
\text { Comparability: } \\
2 \text { stars; } \\
\text { Exposure: } \\
3 \text { stars }\end{array}$ \\
\hline (20) & 2005 & UK & $\begin{array}{l}\text { Case- } \\
\text { control }\end{array}$ & $\begin{array}{l}8,688 \text { cases: } \\
33,923 \\
\text { controls } \\
(\mathrm{MI}, 8,688)\end{array}$ & $7 \mathrm{yr}$ & $\begin{array}{l}37.1 \%: 37.2 \%,<50 \text { yr } 7.6 \%: 7.7 \% \text {, } \\
50-69 \text { yr } 42.4 \%: 42.8 \%, 70-89 \text { yr } \\
50.0 \%: 49.5 \%, 30.1 \%: 12.1 \%, \\
\text { NA. diclofenac } 260: 834, \\
\text { ibuprofen } 176: 656, \text { naproxen } \\
\text { 63:251, indomethacin } 36: 124, \\
\text { piroxicam } 30: 114, \text { ketoprofen } \\
\text { 18:109, fenbufen 16:19, nab- } \\
\text { umetone } 10: 56, \text { mefenamic acid } \\
9: 26 \text {, etodolac } 8: 43, \text { flur-biprofen } \\
6: 34 \text {, tiaprofenic acid } 6: 26\end{array}$ & $\begin{array}{l}\text { Unexposed, } \\
3,203: 13,551\end{array}$ & The first MI & $\begin{array}{l}\text { Selection: } \\
3 \text { stars; } \\
\text { Comparability: } \\
2 \text { stars; } \\
\text { Exposure: } \\
2 \text { stars }\end{array}$ \\
\hline
\end{tabular}


TABLE 9. Continued...

USA

Case-
control

3,859 cases:
10,239

10,239
controls

(MI, 3,859)

(22)

$2004 \quad$ USA

USA

$\begin{array}{cc}\text { Case- } & 1,055 \text { cases: } \\ \text { control } & 4,153 \\ & \text { controls } \\ & (\mathrm{MI}, 1,055)\end{array}$

(23) 2004

$$
\begin{aligned}
& \text { Case- } \\
& \text { control }
\end{aligned}
$$
4,975 cases:
20,000

controls

(MI, 4,975)

52,139
patients-
months:
156,417
patients-
months
1067 days

$97.5 \%( \pm 2.5): 97.6 \%( \pm 0.15)$

male, NA, NA, $100 \%$, ibuprofen

3,859

$2 \mathrm{yr}, 4$

months
$44.5 \% / 34.4 \%: 66.6 \% / 54.7 \%$, $57.01( \pm 9.12) / 58.07( \pm 9.24)$.

$51.14(8.64) / 53.16( \pm 9.46) \mathrm{yr}$, $15.0 \% / 18.8 \%$ : $4.0 \% / 3.7 \%$, 27\%, $30 \%$ (78\% non-prescription NANSAID)

$35 \%, 55 \%>70 \mathrm{yr}, 38 \% / 14 \%$ : $17 \% / 8 \%, 27 \%: 14 \%, 61 \%: 59 \%$

\begin{tabular}{lll}
$\begin{array}{l}\text { Control cohort } \\
\text { (sex, race, age, }\end{array}$ & MI & $\begin{array}{l}\text { Selection: } \\
\text { and LDL }\end{array}$ \\
cholesterol level), & & Compars; \\
10,239 & & 1 stars; \\
& & Exposure: \\
Control (no & MI & Stars \\
history of MI), & & 4 stars; \\
$1,357: 2,796$ & & Comparability: \\
& & 2 stars; \\
& & Exposure: \\
& 2 stars \\
Control cohort & MI & Selection: \\
(sex, age, and & & 3 stars; \\
calendrer year), & & Comparability: \\
20,000 & & 2 stars; \\
& & Exposure: \\
& & 2 stars \\
\hline
\end{tabular}

CV, cardiovascular; GI, gastrointestinal; MI, acute myocardial infarction; LDL, low-density lipoprotein; NA, not available; NOS, Newcastle-Ottawa quality scale. 


\title{
SUPPLIMENTARIES
}

\section{Appendix 1: List of search terms and key words used} \\ 10. (Ibuprofen or naproxen or ketoprofen or flurbiprofen or fenoprofen or oxaprozin or etoldolac or tolmetin or diclofenac or \\ ketorolac or nabumetone or indomethacin or sulindac or piroxicam or meloxicam or mefenamic acid or meclofenamic \\ acid or rofecoxib or celecoxib or veldecoxib or paracoxib or etoricoxib or lumaricoxib).mp. [mp=title, abstract, original \\ title, name of substance word, subject heading word, keyword heading word, protocol supplementary concept word, rare \\ disease supplementary concept word, unique identifier, synonyms] (90791) \\ 11. (cyclooxygenase* or cyclo-oxygenase* or $\mathrm{COX}^{*}$ ).mp. [mp=title, abstract, original title, name of substance word, subject \\ heading word, keyword heading word, protocol supplementary concept word, rare disease supplementary concept word, \\ unique identifier, synonyms] (196883) \\ 12. 5 or 6 or 7 or 8 or 9 or 10 or $11(683969)$ \\ 13. cardiovascular.mp. (517392) \\ 14. myocardial infarction.mp. or exp Myocardial Infarction/ (241926) \\ 15. exp Stroke/ or stroke*.mp. or exp Cerebrovascular Disorders/ (481036) \\ 16. (cardioprotect* or cardio-protect*).mp. [mp=title, abstract, original title, name of substance word, subject heading word, \\ keyword heading word, protocol supplementary concept word, rare disease supplementary concept word, unique \\ identifier, synonyms] (19351) \\ 17. 13 or 14 or 15 or $16(1140235)$ \\ 18. exp Platelet Aggregation/ or platelet*.mp. (262607) \\ 19. blood platelets.mp. or exp Blood Platelets/ (78062) \\ 20. exp Platelet Aggregation Inhibitors/ or exp Platelet Aggregation/ or platelet aggregation inhibit*.mp. or exp Blood \\ Platelets/ (186906) \\ 21. anti platelet effect*.mp. (264) \\ 22. 18 or 19 or 20 or $21(324684)$ \\ 23. 17 or $22(1419931)$ \\ 24. Interaction.mp. (724108) \\ 25. Drug interaction.mp. or exp Drug Interactions/ (164791) \\ 26. Interact*.mp. (1503338) \\ 27. 24 or 25 or $26(1563966)$ \\ 28. 4 and 12 and 23 and 27 (3728) \\ 29. ((NSAID* or Ibuprofen or naproxen or ketoprofen or flurbiprofen or fenoprofen or oxaprozin or etoldolac or tolmetin or \\ diclofenac or ketorolac or nabumetone or indomethacin or sulindac or piroxicam or meloxicam or mefenamic acid or \\ meclofenamic acid or rofecoxib or celecoxib or veldecoxib or paracoxib or etoricoxib or lumaricoxib) adj3 (interact* or \\ inhibit*)).mp. [mp=title, abstract, original title, name of substance word, subject heading word, keyword heading word, \\ protocol supplementary concept word, rare disease supplementary concept word, unique identifier, synonyms] (15311) \\ 30. ((cyclooxygenase* or cyclo-oxygenase* or COX*) adj3 (interact* or inhibit*)).mp. [mp=title, abstract, original title, \\ name of substance word, subject heading word, keyword heading word, protocol supplementary concept word, rare \\ disease supplementary concept word, unique identifier, synonyms] (36297) \\ 31. ((aspirin or ASA or acetylsalicylic acid) adj3 (interact* or inhibit*)).mp. [mp=title, abstract, original title, name of \\ substance word, subject heading word, keyword heading word, protocol supplementary concept word, rare disease \\ supplementary concept word, unique identifier, synonyms] (4517) \\ 32. 29 or 30 or $31(45379)$ \\ 33. 28 and 32 (1161) \\ 34. remove duplicates from 33 (1079)
}




\section{EMBASE}

1. acetylsalicylic acid.mp. or exp acetylsalicylic acid/ (194594)

2. Aspirin.mp. or exp acetylsalicylic acid/ (200287)

3. ASA.mp. or exp acetylsalicylic acid/ (225835)

4. 1 or 2 or $3(235264)$

5. exp nonsteroid antiinflammatory agent/ or NSAID*.mp. (537163)

6. nonsteroidal antiinflammatory.mp. (5560)

7. exp antiinflammatory agent/ or nonsteroidal anti-inflammatory.mp. (1643638)

8. non-steroidal antiinflammatory.mp. (1926)

9. non-steroidal anti-inflammatory.mp. (19822)

10. mefenamic acid.mp. or exp mefenamic acid/ (5640)

11. meclofenamic acid.mp. or exp meclofenamic acid/ (2834)

12. (ibuprofen or naproxen or ketoprofen or flurbiprofen or fenoprofen or oxaprozin or etoldolac or tolmetin or diclofenac or ketorolac or nabumetone or indomethacin or sulindac or piroxicam or meloxicam or rofecoxib or celecoxib or veldecoxib or paracoxib or etoricoxib or lumaricoxib).mp. [mp=title, abstract, heading word, drug trade name, original title, device manufacturer, drug manufacturer, device trade name, keyword, floating subheading word] (166401)

13. (cyclooxygenase* or cyclo-oxygenase* or $\mathrm{COX}^{*}$ ).mp. [mp=title, abstract, heading word, drug trade name, original title, device manufacturer, drug manufacturer, device trade name, keyword, floating subheading word] (284223)

14. 5 or 6 or 7 or 8 or 9 or 10 or 11 or 12 or $13(1876062)$

15. cardiovascular.mp. (874842)

16. myocardial infarction.mp. or exp heart infarction/ (378320)

17. stroke*.mp. (370234)

18. Cerebrovascular.mp. or exp cerebrovascular disease/ (556732)

19. (cardioprotect* or cardio-protect).mp. [mp=title, abstract, heading word, drug trade name, original title, device manufacturer, drug manufacturer, device trade name, keyword, floating subheading word] (25495)

20. 15 or 16 or 17 or 18 or $19(1726649)$

21. platelet*.mp. (291091)

22. blood platelets.mp. or exp thrombocyte/ (104209)

23. Platelet Aggregation Inhibitors.mp. or exp antithrombocytic agent/ (314999)

24. Platelet Aggregation.mp. or exp thrombocyte aggregation/ (61352)

25. platelet aggregation inhibit*.mp. (2390)

26. anti platelet effect*.mp. (421)

27. 21 or 22 or 23 or 24 or 25 or $26(586844)$

28. 20 or 27 (2171471)

29. exp drug interaction/ or Interaction.mp. (1524352)

30. Interact*.mp. (1914430)

31. 29 or 30 (2067908)

32. 4 and 14 and 28 and 31 (17752)

33. ((NSAID* or Ibuprofen or naproxen or ketoprofen or flurbiprofen or fenoprofen or oxaprozin or etoldolac or tolmetin or diclofenac or ketorolac or nabumetone or indomethacin or sulindac or piroxicam or meloxicam or mefenamic acid or meclofenamic acid or rofecoxib or celecoxib or veldecoxib or paracoxib or etoricoxib or lumaricoxib) adj3 (interact* or inhibit*)).mp. [mp=title, abstract, heading word, drug trade name, original title, device manufacturer, drug manufacturer, device trade name, keyword, floating subheading word] (17171)

34. ((cyclooxygenase* or cyclo-oxygenase* or COX*) adj3 (interact* or inhibit*)).mp. [mp=title, abstract, heading word, drug trade name, original title, device manufacturer, drug manufacturer, device trade name, keyword, floating subheading word] (43788)

35. ((aspirin or ASA or acetylsalicylic acid) adj3 (interact* or inhibit*)).mp. [mp=title, abstract, heading word, drug trade name, original title, device manufacturer, drug manufacturer, device trade name, keyword, floating subheading word] (5681) 33 or 34 or $35(55160)$

36. 32 and 36 (3017)

37. remove duplicates from 37 (2965) 

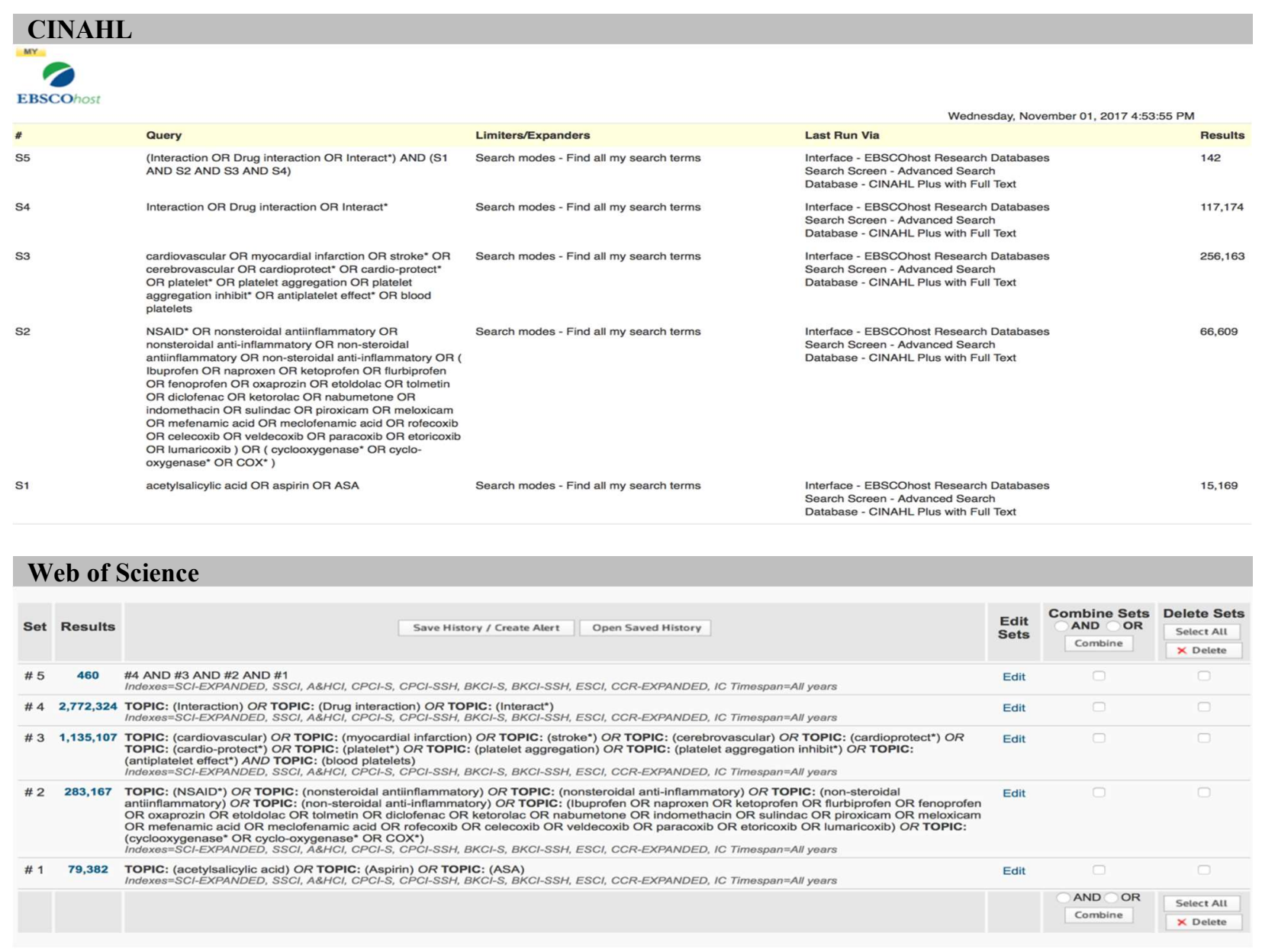

\section{EBM Reviews search (via Wiley)}

Search Name: acetylsalicylic acid or Aspirin or ASA in Title, Abstract, Keywords and NSAID* or nonsteroidal antiinflammatory or nonsteroidal anti-inflammatory or non-steroidal antiinflammatory or non-steroidal anti-inflammatory or Ibuprofen or naproxen or ketoprofen or flurbiprofen or fenoprofen or oxaprozin or etoldolac or tolmetin or diclofenac or ketorolac or nabumetone or indomethacin or sulindac or piroxicam or meloxicam or mefenamic acid or meclofenamic acid or rofecoxib or celecoxib or veldecoxib or paracoxib or etoricoxib or lumaricoxib or cyclooxygenase* or cyclo-oxygenase* or COX* and cardiovascular or myocardial infarction or stroke* or cerebrovascular or cardioprotect* or cardio-protect* or platelet* or platelet aggregation or platelet aggregation inhibit* or antiplatelet effect* or blood platelets and Interaction or Drug interaction or Interact* (Word variations have been searched)

Last Saved: $\quad$ 01/11/2017 22:00:04.558

ID Search

\#1 acetylsalicylic acid or Aspirin or ASA:ti,ab,kw and NSAID* or nonsteroidal antiinflammatory or nonsteroidal antiinflammatory or non-steroidal antiinflammatory or non-steroidal anti-inflammatory or Ibuprofen or naproxen or ketoprofen or flurbiprofen or fenoprofen or oxaprozin or etoldolac or tolmetin or diclofenac or ketorolac or nabumetone or indomethacin or sulindac or piroxicam or meloxicam or mefenamic acid or meclofenamic acid or rofecoxib or celecoxib or veldecoxib or paracoxib or etoricoxib or lumaricoxib or cyclooxygenase* or cyclo-oxygenase* or COX* and cardiovascular or myocardial infarction or stroke* or cerebrovascular or cardioprotect* or cardio-protect* or platelet* or platelet aggregation or platelet aggregation inhibit* or antiplatelet effect* or blood platelets and Interaction or Drug interaction or Interact* (Word variations have been searched) 
Results: 160

1. Cochrane Database of Systematic Reviews (25)

2. Database of Abstracts of Reviews of Effect (1)

3. Cochrane Central Register of Controlled Trials (134)

4. Cochrane Methodology Register (0)

5. Health Technology Assessment Database (0)

6. NHS Economic Evaluation Database (0)

7. About the Cochrane Collaboration (0)

\section{PubMed (March 15, 2018)}

This searched aimed to screen for any relevant studies published after October 2017. We, therefore, carried out PubMed search using the following keywords "NSAID AND Aspirin" and restricted to publication date from 2017/11/01 to 2018/03/15. We found 88 studies, and none met the inclusion criteria of this review. On May 1, 2018 another search was carried out that resulted in no eligible study. 


\section{Grey Literature Search}

\section{Database/}

Website Name

\section{Date}

searched

\section{Search terms used}

acetylsalicylic acid OR Aspirin OR ASA in Title, Abstract

Keywords and NSAID* OR nonsteroidal antiinflammatory OR

nonsteroidal anti-inflammatory OR non-steroidal antiinflammatory

OR non-steroidal anti-inflammatory OR Ibuprofen OR naproxen OR

ketoprofen OR flurbiprofen OR fenoprofen OR oxaprozin OR

etoldolac OR tolmetin OR diclofenac OR ketorolac OR nabumetone

OR indomethacin OR sulindac OR piroxicam OR meloxicam OR

Register of

Controlled Trials

(CENTRAL)

http://onlinelibrary.wiley.com /cochranelibrary/search

01-Nov-17 mefenamic acid OR meclofenamic acid OR rofecoxib OR celecoxib OR veldecoxib OR paracoxib OR etoricoxib OR lumaricoxib OR cyclooxygenase* OR cyclo-oxygenase* OR COX* and cardiovascular OR myocardial infarction OR stroke* OR cerebrovascular OR cardioprotect* OR cardio-protect* OR platelet* OR platelet aggregation OR platelet aggregation inhibit* OR antiplatelet effect* OR blood platelets and Interaction OR Drug interaction OR Interact*

all(acetylsalicylic acid OR Aspirin OR ASA) AND all(NSAID* OR nonsteroidal antiinflammatory OR nonsteroidal anti-inflammatory OR non-steroidal antiinflammatory OR non-steroidal antiinflammatory OR Ibuprofen OR naproxen OR ketoprofen OR flurbiprofen OR fenoprofen OR oxaprozin OR etoldolac OR tolmetin OR diclofenac OR ketorolac OR nabumetone OR indomethacin OR sulindac OR piroxicam OR meloxicam OR

https://search-proquest-com.login.

ProQuest

Dissertations \&

Theses Global pexy.library.ualberta.ca/ pqdtglobal/results/ D2EEE14FBB414B59PQ/ 1 ? accountid $=14474$

https://health-products.canada.ca/ ctdb-bdec/search-recherche.do; jsessionid=1D954BB5AFD48D4326 64B0D0818697F4
02-Nov-17 mefenamic acid OR meclofenamic acid OR rofecoxib OR celecoxib OR veldecoxib OR paracoxib OR etoricoxib OR lumaricoxib OR cyclooxygenase* OR cyclo-oxygenase* OR COX*) AND all(cardiovascular OR myocardial infarction OR stroke* OR cerebrovascular OR cardioprotect* OR cardio-protect* OR platelet* OR platelet aggregation OR platelet aggregation inhibit* OR antiplatelet effect* OR blood platelet) AND all(Interaction OR Drug interaction OR Interact*)

Medical Condition: cardiovascular OR cerebrovascular

Drug Name: acetylsalicylic acid OR Aspirin AND NSAID
Health Canada's

Clinical Trials

Database
\# of Relevant

Documents

\section{Comments}

We added this

to the

Cochrane

library search

results as the

CENTRAL is

one database

included in

Cochrane

library

We added all

16 to the

additional

records

identified

through other

sources 


\section{PROSPERO}

International

prospective

register of

https://www.crd.york.ac.uk/ PROSPERO/\#searchadvanced

systematic reviews acetylsalicylic acid OR Aspirin OR ASA AND NSAID* OR nonsteroidal antiinflammatory OR nonsteroidal anti-inflammatory OR non-steroidal antiinflammatory OR non-steroidal antiinflammatory OR Ibuprofen OR naproxen OR ketoprofen OR flurbiprofen OR fenoprofen OR oxaprozin OR etoldolac OR

tolmetin OR diclofenac OR ketorolac OR nabumetone OR indomethacin OR sulindac OR piroxicam OR meloxicam OR mefenamic acid OR meclofenamic acid OR rofecoxib OR celecoxib OR veldecoxib OR paracoxib OR etoricoxib OR lumaricoxib OR cyclooxygenase* OR cyclo-oxygenase* OR COX* AND cardiovascular OR myocardial infarction OR stroke* OR cerebrovascular OR cardioprotect* OR cardio-protect* OR platelet* OR platelet aggregation OR platelet aggregation inhibit* OR antiplatelet effect* OR blood platelet AND Interaction OR Drug interaction OR Interact* 
TITLE

Title

1 Identify the report as a systematic review, meta-analysis, or both.

ABSTRACT

Structured summary

2 Provide a structured summary including, as applicable: background; objectives; data sources; study eligibility criteria, participants, and interventions; study appraisal and synthesis methods; results; limitations; conclusions and implications of key findings; systematic review registration number.

\section{INTRODUCTION}

\section{Rationale}

Objectives

\section{METHODS}

Protocol and registration

Eligibility criteria

Information sources

Search

Study selection

Data collection process

Data items

Risk of bias in individual studies

Summary measures
3 Describe the rationale for the review in the context of what is already known.

4 Provide an explicit statement of questions being addressed with reference to participants, interventions, comparisons, outcomes, and study design (PICOS).

5 Indicate if a review protocol exists, if and where it can be accessed (e.g., Web address), and, if available, provide registration information including registration number.

6 Specify study characteristics (e.g., PICOS, length of follow-up) and report characteristics (e.g., years considered, language, publication status) used as criteria for eligibility, giving rationale.

7 Describe all information sources (e.g., databases with dates of coverage, contact with study authors to identify additional studies) in the search and date last searched.

8 Present full electronic search strategy for at least one database, including any limits used, such that it could be repeated.

State the process for selecting studies (i.e., screening, eligibility, included in systematic review, and, if applicable, included in the meta-analysis).

10 Describe method of data extraction from reports (e.g., piloted forms, independently, in duplicate) and any processes for obtaining and confirming data from investigators.

11 List and define all variables for which data were sought (e.g., PICOS, funding sources) and any assumptions and simplifications made.

12 Describe methods used for assessing risk of bias of individual studies (including specification of whether this was done at the study or outcome level), and how this information is to be used in any data synthesis.

13 State the principal summary measures (e.g., risk ratio, difference in means) 
Synthesis of results

Risk of bias across studies

Additional analyses

\section{RESULTS}

Study selection

Study characteristics

Risk of bias within studies

Results of individual studies

Synthesis of results

Risk of bias across studies

Additional analysis

\section{DISCUSSION}

Summary of evidence

Limitations

Conclusions

FUNDING

Funding
14 Describe the methods of handling data and combining results of studies, if done, including measures of consistency (e.g., $\left.\mathrm{I}^{2}\right)$ for each meta-analysis.

15 Specify any assessment of risk of bias that may affect the cumulative evidence (e.g., publication bias, selective reporting within studies).

16 Describe methods of additional analyses (e.g., sensitivity or subgroup analyses, meta-regression), if done, indicating which were pre-specified.

17 Give numbers of studies screened, assessed for eligibility, and included in the review, with reasons for exclusions at each stage, ideally with a flow diagram.

18 For each study, present characteristics for which data were extracted (e.g., study size, PICOS, follow-up period) and provide the citations.

19 Present data on risk of bias of each study and, if available, any outcome level assessment (see item 12).

20 For all outcomes considered (benefits or harms), present, for each study: (a) simple summary data for each intervention group (b) effect estimates and confidence intervals, ideally with a forest plot.

21 Present results of each meta-analysis done, including confidence intervals and measures of consistency.

22 Present results of any assessment of risk of bias across studies (see Item 15).

23 Give results of additional analyses, if done (e.g., sensitivity or subgroup analyses, meta-regression [see Item 16).

24 Summarize the main findings including the strength of evidence for each main outcome; consider their relevance to key groups (e.g., healthcare providers, users, and policy makers).

25 Discuss limitations at study and outcome level (e.g., risk of bias), and at review-level (e.g., incomplete retrieval of identified research, reporting bias).

26 Provide a general interpretation of the results in the context of other evidence, and implications for future research.

27 Describe sources of funding for the systematic review and other support (e.g., supply of data); role of funders for the systematic review.

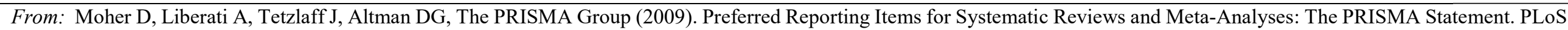
Med 6(6): e1000097. doi:10.1371/journal.pmed1000097 